

\section{Automatic Measurement of Water Levels Within the 300-FF-5 Boundary}
M. D. Campbell
D. R. Newcomer

April 1992

Prepared for the U.S. Department of Energy under Contract DE-AC06-76RLO 1830

Pacific Northwest Laboratory

Operated for the U.S. Department of Energy by Battelle Memorial Institute

\section{Battelle}




\title{
DISCLAIMER
}

This report was prepared as an account of work sponsored by an agency of the United States Government. Neither the United States Government nor anly agency thereof, nor Battelle Memorial Institute, nor any of their employees, makes any warranty, expressed or implied, or assumes any legal liability or responsibility for the accurasy, completeness, or usefulness of any information, apparatus, product, or process disclosed, or represents that its use would not infringe privately owned rights. Reference herein to any specific commercial product, process, or service by trade name, trademark, manufacturer, or olherwise does not necessarily constitute or imply its endorsement, recommendation, or favoring by the United States Governinent or any agency thereof, or Ballelle Memorial Institute. The views and opinions of authors expressed herein do not necessarily state or reflect those of the United States Government or any agency thereof.

\author{
PACIFIC NORTHWEST LABORATORY \\ operated by \\ BATTELLE MEMORIAL INSTITUTE \\ for the \\ UNITED STATES DEPARTMENT OF ENERGY \\ under Contract DE-ACO6-76RLO 1830
}

Printed in the United States of America

Available to DOE and DOE contractors from the

Office of Scientific and Technical ir mation, P.O. Box 62, Oak Ridge, TN 37831; prices available from (615) $576-8401$. Fis $626-8401$.

Available to the public from the National Technical In formation Service, U.S. Department of Commerce, 52135 Port Royal Rd., Springfield, VA 22161. 
PNL--7874

DE92 013160

AUTOMATIC MEASUREMENT OF WATER LEVELS

WITHIN THE 300-FF-5 BOUNDARY

M. D. Campbe 11
D. R. Newcomer

Apri1 1992

Prepared for

the U.S. Department of Energy

under Contract DE-AC06-\%6RLO 1830

Pacific. Northwest Laboratory

Richland, Washington 99352 
A network of pressure transducers with dataloggers and radio transceivers was designed to monitor water levels in 42 wells within the CERCLA $300-F F-5$ boundary in the 300 Area at the Hanford Site. Automatic datalogging, radio retrieval, and computer processing provide hourly measurements that appear precise within $\pm 0.02 \mathrm{ft}$ at a cost expected to be less than $\$ 1$ each compared with $\$ 9$ each for steel-tape measurements made manually. Laboratory and field results both confirm that precision is half of that originally specified. This report is intended as a reference to be used in operating and maintaining the monitoring system. The report includes water-level measurements from the first eight wells monitored. 


\section{CONTENTS}

SUMMARY

1.0 INTRODUCTION . . . . . . . . . . . . . . . . . 1.1

2.0 MATERIALS AND METHODS ..................... 2.1

2.1 EQUIPMENT SPECIFICATIONS AND OPERATIONAL CHECKOUT . . . . . 2.1

2.1.1 Transducers ................ 2.1

2.1 .2 Dataloggers ............... 2.4

2.1.3 Radic: and Other Support Equipment . . . . . . . 2.6

2.2 EQUIPMENT INSTALLATION REVIEW AND FIELD TESTS . . . . . . . 2.7

2.2.1 Monitoring System Design and Layout . . . . . . . 2.8

2.2.2 System Calibration In the Field . . . . . . . . 2.11

3.0 RESULTS AND DISCUSSION . . . . . . . . . . . . . . . . 3.1

3.1 EQUIPMENT OPERATIONAL CHECKOUT . . . . . . . . . . . 3.1

3.1.1 Radio System Test Results ............. 3.1

3.1.2 Datalogger Test Results . . . . . . . . . . 3.1

3.1.3 Water Column Transducer Test Results . . . . . . . 3.3

3.2 COMMENTS ON INSTALLATION WITH RESULTS FROM FIELD TESTS " • 3.5

3.2.1 Results and Conclusions from System
Functional Checkout ................ 3.6

3.2.2 Field Calibration Results . . . . . . . . . 3.6

3.2.3 Use of Prestructured Processing and Data Files . . . 3.13

3.2.4 Field Measurements . . . . . . . . . . . 3.13

4.0 CONCLUSIONS . . . . . . . . . . . . . . . . . . 4.1

5.0 REFERENC.ES ........................ . . . 5.1

APPENDIX . . . . . . . . . . . . . . . . . . . A.1 


\section{FIGURES}

1.1 Master Well Map Showing 300-FF-5 Boundary . . . . . . . . . . 1.2

2.1 Wide-Range Calibration Test Stand . . . . . . . . . . . 2.2

2.2 Transducer Calibration Fixture . . . . . . . . . . . . 2.4

2.3 In Situ Calibrator for Pressure Transducers, to be Used with Standard Spacers for Calibration in Place . . . . . . . . 2.12

3.1 Datalogger Resolution in Response to 11 Changes in Voltage of 0.1 Microvolt Each ............ . . 3.3

3.2 Wide-Range Calibration Test Results, Showing Pressure Transducer Deviations from Steel-Tape Readings When Transducers Were Tested in Over-Range Conditions

3.3 Results from Calibration of Pressure Transducers SN400808 and SN409776 in a Standard Jarrel . . . . . . . . 3.5

3.4 Results of In Situ Calibration for Well 399-1-8 on Day 214, 1991

3.5 Results of In Situ Calibration for Well 399-1-9 on Day 214,1991

3.6 Results of In Situ Calibration for Well 399-1-16B on Day 204, 1991

3.7 Results of In Situ Calibration for Well 399-1-18A on Day 214, 1991

3.8 Results of In Situ Calibration for Well 399-1-18B on Day 214, 1991

3.9 Results of In Situ Calibration for Well 399-1-18C on Day 214, 1991

3.10 Results of In Situ Calibration for Well 399-3-9 on Day 214, 1991

3.11 Results of In Situ Calibration for Well 399-4-9 on Day 214, 199

3.12 Deviations of Transducer Measurements from Corresponding Steel-Tape Measurements

3.13 Example Layout of the Prestruc'. 'Ired Spreadsheet File for Processing Data 
3.14 Example Layout of the Pre-Structured Spreadsheet File for Processing In Situ Calibration Data ............

3.15 Comparison of Routine Transducer Measurements and Steel-Tape Measurements of Depth to Water Below the Top of the Casing for Well 399-1-8

3.16 Comparison of Routine Transducer Measurements and Steel-Tape Measurements of Depth to Water Below the Top of the Casing for Well 399-1-9 . . . . . . . . . . . .

3.17 Comparison of Routine Transducer Measurements and Steel-Tape Measurements of Depth to Water Below the Top of the Casing for We11 399-1-16B

3.18 Comparison of Routine Transducer Measurements and Steel-Tape Measurements of Depth to Water Below the Top of the Casing for We11 399-1-18A

3.19 Comparison of Routine Transducer Measurements and Steel-Tape Measurements of Depth to Water Below the Top of the Casing for Well 399-1-18B . . . . . . . . . . .

3.20 Comparison of Routine Transducer Measurements and Steel-Tape Measurenents of Depth to Water Below the Top of the Casing for We11 399-1-18C

3.21 Comparison of Rout ine Transducer Measurements and Steel-Tape Measurerients of Depth to Water Below the Top of the Casing for We11 399-3-9

3.22 Comparison of Routine Transducer Measurements and Steel-Tape Measurements of Depth to Water Below the Top of the Casing for Well 399-4-9 . . . . . . . . . . . . 


\section{TABLES}

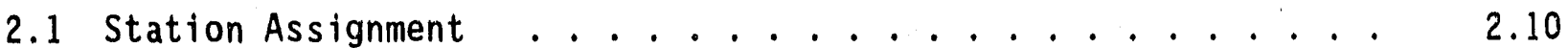

3.1 Fraction of Specified Tolerance that Each Station Reading Deviated from Its Expected Reading in Each Range . . . . . . . 3.

3.2 Summary of Calibration Factors for Wells 399-1-8, 399-1-9, 399-1-16B, 399-1-18A, 399-1-18B, 399-1-18C, 399-3-9, and $399-4-9$

3. 11 


\subsection{INTRODUCTION}

During FY 1991, at the request of Westinghouse Hanford Company, Pacific Northwest Laboratory (PNL) established a groundwater-elevation monitoring network for the 300-FF-5 operable unit. The automated system was designed to measure and store water-level data and transmit the data on demand by radio telemetry to a central computer for processing and storage. The network design calls for pressure transducers and dataloggers coupled to radio frequency (RF) transceivers to monitor 42 of the wells and 2 of the river stations within the 300-FF-5 boundary in the 300 Area (see Figure 1.1).

Automatic measurement with RF telemetry is potentially more costeffective and reliable than manual measurements using steel tape (Campbel1 et al. 1991) and provides more useful data for site characterization. Greater cost effectiveness and reliability depended on stability and reliability of the transducers and dataloggers and on the frequency of measurements. Stability and reliability of the transducer and datalogger are ensured in the current systems in the 300 Area by incorporating an in situ calibrator, which provides for calibration of the entire system without removing the transducer from the well or river location and without disconnecting the datalogger. Thus, the system, including datalogger and transducer, is subject to calibration at any time, in place.

The type of systems selected were previously field tested. An in situ calibrator was included and each system component was checked and calibrated in the laboratory before it was installed in the field. The remainder of this report discisses the materials and methods used and the results obtained. Water-level measurements are included from the first eight wells that were automated. 


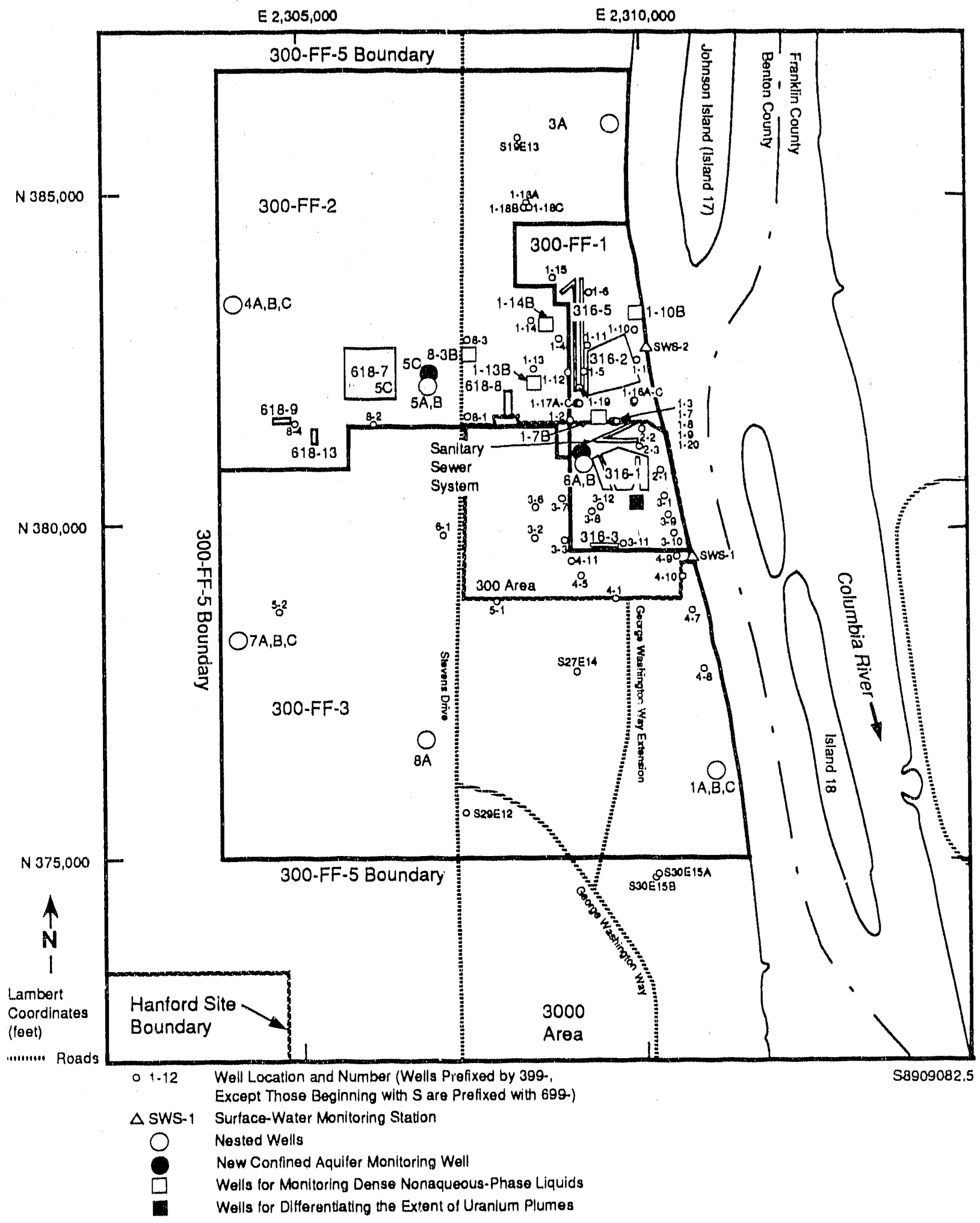

FIGURE 1.1. Master We11 Map Showing 300-FF-5 Boundary 


\subsection{MATERIALS AND METHOOS}

Laboratory and field tests are described under two general headings. First, equipment selection, preparation, and preinstallation testing are discussed. Second, field installation, testing, and measurements are presented.

\subsection{EQUIPMENT SPECIFICATIONS AND OPERATIONAL CHECKOUT}

Over-range tests were designed to test linearity in the systems over the maximum expected range of use. Narrow-range tests were designed to ensure conformance of transducers to manufacturer specifications. All system tests were run using randomly selected components, configured as they would be in the field.

\subsubsection{Transducers}

Pressure transducer selection was based on the need to measure water levels within $\pm 0.01 \mathrm{ft}$. This tolerance satisfies requirements specified by the Environmental Protection Agency (EPA), in the Technical Enforcement Guidance Document (1986).

\section{Specifications}

Transducers were procured to conform to the following specifications:

Size: length $\leq 12$ in., diameter $\leq 1$ in.

Type: Wheatstone full bridge silicon straingage, configured for actual excitation voltage readout

Enclosure: corrosion resistance $\geq 316 \mathrm{~L}$ stainless steel

Range: $\geq 10$ psi when fully overpressured

Resolution: $0.0001 \mathrm{psig}$

Error: $\leq 0.003 \mathrm{psig}$ within a temperature variation of $18^{\circ} \mathrm{F}$

Excitation Range: 5 to $12 \vee D C$

Erficiency (Output/Input): $\geq 0.001$

Electric Cables: chemically inert, waterproof, abrasion resistant jacket, 100-ft, 6-wire, with atmospheric vent tube(s), molded or sealed to transducer, fitted with exchangeable silica-gel desiccator, dried and sealed following manufacture with desiccator active during shipment. 


\section{Wide-Range, Preinstallation Tests}

A $21-\mathrm{ft}$ tall water column was constructed, 11ke the one shown in Figure 2.1. A 1.25-in. $x$ 21-ft pipe was supported vertically by a tripod. A 1.5-in. dia. $\times$ 6-in. long metal sleeve was slipped over the pipe. A flexible plastic capillary tube, with a U-shaped copper drip tube inserted into it was fastened to the sliding metal sleeve. The other end of the capillary tube was connected to the transducer manifold. A steel-tape casing with spring retractor was fastened to the bottom end of the 21-ft pipe, and the end of the steel tape was also fastened to the steel sleeve. A nylon cord was looped through two pulleys, one at the top and one at, the bottom of the $21-\mathrm{ft}$ pipe, and was fastened to the metal sleeve to move the sleeve vertically up and down the pipe.

A transducer manifold with a water reservoir and a screw-driven piston was mounted on one leg of the tripod in a position to allow air to escape froll

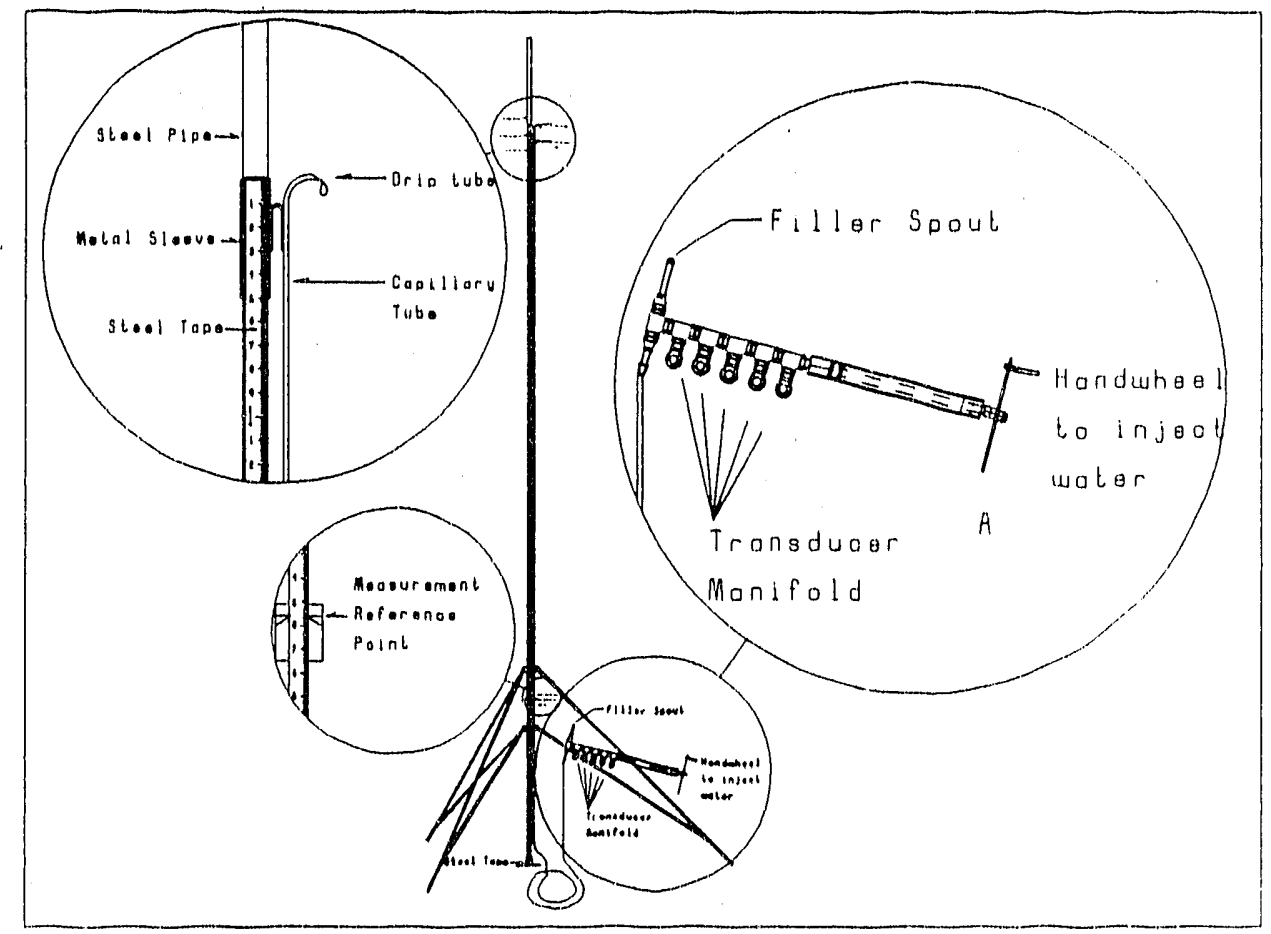

FIGURE 2.1. Wide-Range Calibration Test Stand. Drip tube and steel tape are e,evated together above the zero point. Water is injected by turning handwheel "A" until water falls from the drip tube. Transducer reading and steel-tape reading are recorded. 
the filler spout. After installing the transducers and retracting the screwdriven piston by turning it counterclockwise, the manifold was filled with water and sealed. The sliding metal sleeve was moved to its lowest initial position, and a steel-tape reading was recorded. The screw handwheel on the manifold, denoted in the diagram as "A," was then turned clockwise until water dripped from the drip tube. The transducer readings were recorded. The sliding metal sleeve was then raised to a second desired elevation, and the steel-tape reading was recorded. Handwheel " $A$ " was again rotated clockwise until water dripped from the drip tube. Transducer readings were recorded.

The following equation was used to obtain a calibration factor (CF):

$$
C F=(M 1-M 2) / X 1-X 1)
$$

where $M 1$ and $M 2$ are steel-tape (or spacer) measurements 1 and 2 , and $X 1$ and $X 2$ are transducer measurements 1 and 2 .

\section{Narrow-Range, Preinstallation Tests}

Transducers were calibrated in a tank of distilled water to check for precision, bias, linearity, and hysteresis. A schematic diagram of the calibration tank is shown in Figure 2.2. The standard calibration tank is described in detail in Campbell et al. (1991).

Transducers were displaced vertically in distilled water at exactly 0.5-ft intervals for $2.5 \mathrm{ft}$ by turning the lead screw until appropriate graduations were aligned on the micrometer. Each mark on the micrometer represents 0.001 in. Each turn of the lead screw moves the carriage vertically $0.1 \mathrm{in}$. Thus, 60 turns moves the carriage $6 \mathrm{in.}$, or $0.5 \mathrm{ft}$, with a resolution of $0.0005 \mathrm{ft}$. Each turn was recorded by an electronic counter.

Six transducers were fastened into the mounting fixture and connected to standardized dataloggers. The mounting fixture remained in air for at least 1 min while readings were recorded every $2 \mathrm{~s}$. The mounting fixture was then lowered until all transducers were barely submerged (this was called the zero depth reading). Again readings were recorded every $2 \mathrm{~s}$ for $1 \mathrm{~min}$. The 


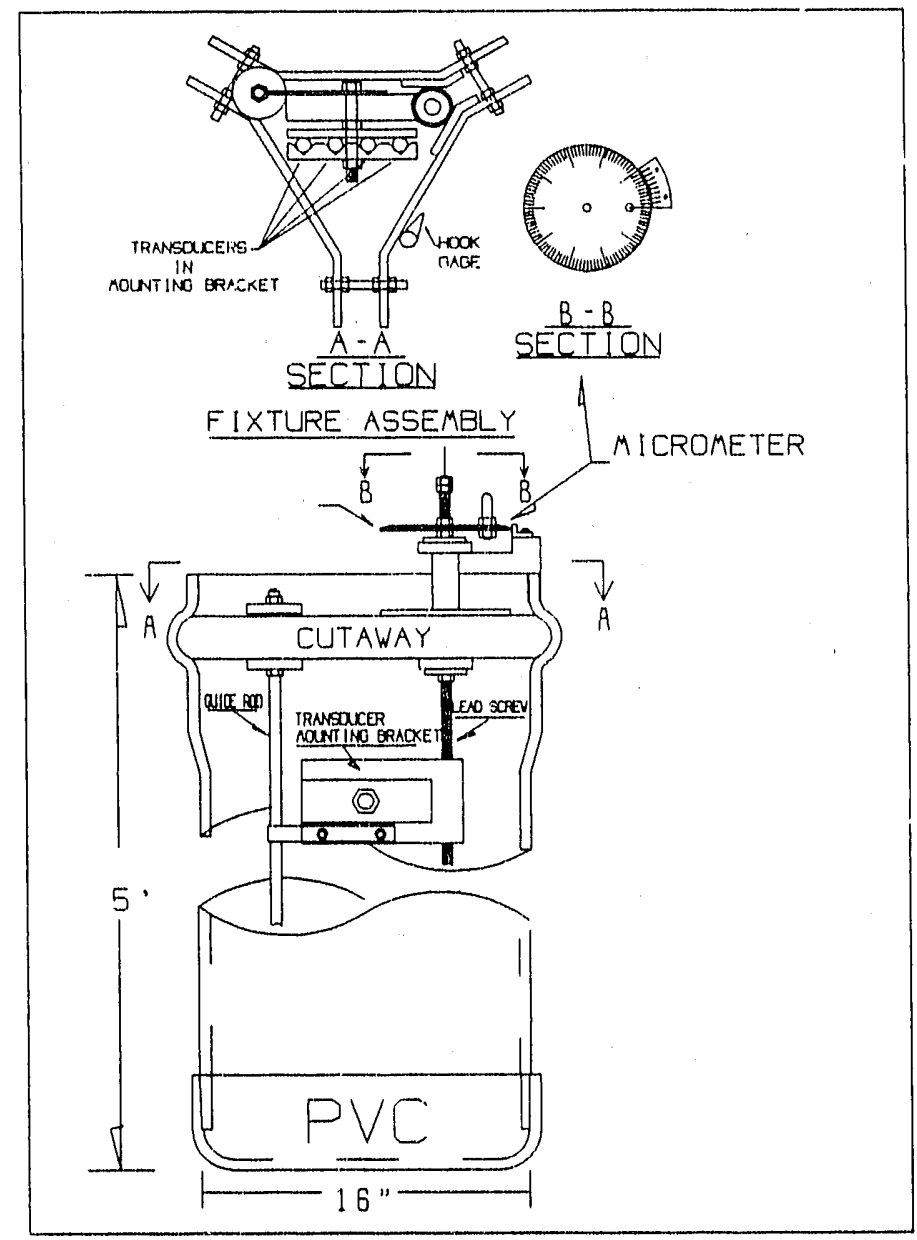

\section{FIGURE 2.2. Transducer Calibration Fixture}

carriage was lowered and readings recorded at $0.5-\mathrm{ft}, 1-\mathrm{ft}, 1.5-\mathrm{ft}, 2-\mathrm{ft}$, and 2.5-ft depths. The carriage was raised, following the reverse procedure, until the reading in air was recorded. Data were loaded on a computer, formatted, and processed instantly in a pre-structured spreadsheet with graphic output that displayed deviations of transducer output from expected values, all in feet.

\subsubsection{Dataloggers}

Dataloggers specifications were sent to vendors and bids were received. Before field installation, dataloggers were tested for conformance to specifications and to ascertain resolution and repeatability. The readings were compared with those from a calibrated microvoltmeter. Finally, a test was run 
to yerify that voltage ratios of (transducer output $\times 1000) /($ excitation) were equal or superior to output measurements taken alone, even with precise voltage excitation.

\section{Specifications}

Datalogger characteristics identified during the laboratory and field tests include the following:

Type: Analog voltage sampling with $A / D$ conversion and digital storage at selectable precision; to interface with RF radio link for data recovery

Enclosure: Rain-tight, (not vapor or air tight) with adequate solar shield

Electrical Isolation: Optical or spark-gap isolation for electrical surge protection

Range: Actorange or manually selectabie to cover values from 4,000 to a, 000,000 $\mathrm{x}$; resolution in multiples $\leq 10$

Resolution: $\geq 1$ part in 4,000 ( $\geq 12$ bit)

Error: $\leq 0.6 \mu$ Volts on most sensitive range

Power Supply: Programmable precision supply voltage for transducer excitation, such that transducer efficiency/resolution $\geq 4,000$, with variation $\leq 1$ part in 8,000

Control Capability: at least three relay control ports capable of actuation through programmable "IF" statements

Sample Rate: $\geq 10 / \mathrm{s}$

Internal clock: Capable of posting year, day, hour, minute, and second in data memory with error less than $2 \mathrm{ppm}$ for each reading.

Common Mode Rejection: for $60 \mathrm{~Hz}$

Operating Temperature Range: -25 to $140^{\circ} \mathrm{F}$, with $<1$ part in 4,000 uncompensated error

Humidity Tolerance: operable from 0 to $100 \%$ and condensing for at least $1 \mathrm{hr}$

Data Storage Capacity: $\geq 8760$ datapoints with 5 -place precision, plus date and time

Data Retrieval Capability: Order of preference: 1) RF link (REQUIRED), 2) audio cassette tape, 3) storage module, or 4) portable computer. 


\section{Comparison with Standardized Multimeter}

Voltages from a mercury cell and from a precision power supply were divided by two precision decade resistors configured for center tap output. The readings taken by a standards-caltbrated microvoltmeter were compared with readings taken by the dataloggers.

\section{Resolution Tests}

A precision decade resistor in series with an alkaline cell provided small voltage changes to test the resolution of the dataloggers. These voltage changes were also measured by a mete: with $1 \mu V$ resolution and a meter with $0.1 \mu \mathrm{V}$ resolution. Selected voltage divisions were small enough to demonstrate datalogger resolution. It was possible, therefore, to characterize datalogger resolution as a set of deviations from a standard voltage value, thus proving the precision of each datalogger.

\section{Volt-Ratio Processing to Minimize Error}

The dataloggers selected were configured to read the output voltage and the excitation voltage in rapid succession, which makes measurement accuracy unnecessary if precision is adequate. Thus, by measuring the transducer voltage ratio, the supply voltage was varied from 2500 to $1500 \mathrm{mV}$ without any measurable effect on the voltage ratio. This feature requires excitation and datalogger measurement stability for the few microseconds necessary to make the measurements, thus avoiding datalogger errors resulting from temperature and discharge of the battery or power supply.

\subsubsection{Radios and Other Support Equipment}

Components of the telemetry system for each monitoring station include a radio, modem, antenna and mast, solar panel, power supply, and instrument shelter. The radios were supplied as part of the telemetry system provided by the datalogger vendor. They are 5-W, hand-held, two-channel transceivers, with a crystal-controlled frequency set at $419.990625 \mathrm{MHz} \pm 2.5 \mathrm{kHz}$.

\section{Specifications}

Support equipment specifications included the following:

Compatibility: Support equipment shall be compatible with dataloggers and transducers 
Instrument Tower: Tripod to hold antenna mast, instrument shelter, and solar panel, tether cables for antenna mast, swage collars to fit cables, anchor posts for tripod, copper ground rod with rod-to-mast ground wire, clamps for ground wire and anchor posts.

Power Supply: Solar panel with mounting bracket, with power output suitable for daily dita retrieval from datalogger with radio frequency (RF) link in southcentral Washington winter solar insolation; regulator to keep voltage within proper limits for datalogger, battery, and radio. Deep cycle, lead-acid battery with 40 to $80 \mathrm{~A}$-hr capacity. Enclosure and lid for the battery.

Radio Link: Hand-held, 5-W, FM transceiver with programmable or crystal frequency selection within $\pm 2.5 \mathrm{kHz}$ of frequency specified in the license; RF modem; omnidirectional anterina with fittings; coaxial cable to reach from radio to antenna, with fittings. (Note: Each of the above 4 items plus power supply and enclosure for one base station.)

Computer: Portable, IBM compatible, with math coprocessor, at least 3 MB RAM, 40 MB hard disk and 1.44 MB floppy, capable of at least $6 \mathrm{hr}$ continuous operation without battery recharge, with display clearly readable in direct sunlight.

Computer Software: Suitable io interrogate dataloggers via RF radio link through RS232C serial port and to place data in a file readable by Lotus, Microsoft, and Borland spreadsheets operating in IBM compatible environment.

\section{Radio and Antenna Tests}

A radio and a lead-acid battery were installed in each of the 30 datalogging systems. Each system in turn was uniquely identified by assigning a binary number to its RF modem. In the laboratory a computer connected to the base station called each system in turn on the RF link to test radio response. Boeing Radio Maintenance personnel tested the frequency of each transceiver for the authorized $419.990625 \mathrm{MHz} \pm 2.5 \mathrm{kHz}$. Boeing personnel also tested power output and antenna reflectance.

\subsection{EQUIPMENT INSTALLATION REVIEW AND FIELD TESTS}

Following functional testing to prove compliance with specifications, equipment was selected and installed at each well site, after the site was cleared for installation. Monitoring system design, layout, and components are discussed below, with comments and details on operation. Also discussed are the procedures followed to perform in situ calibration. 


\subsubsection{Monitoring System Design and Layout}

The monitor:ng system consists of a base station and several field stations. Each field station serves one to three wells. An in situ calibrator was used to suspend a transducer into water in each wel1. Each system component required functional checkout.

\section{Base Station}

The base station consists of a 12-V power supply, an RF modem, an FM transceiver, a 1.25-in. galvanized-pipe mast with antenna and coaxial lead-in cable, and a computer with an RS?32C port and datalogger communication support software.

\section{We11 Station Composition, Assembly, and Adjustment}

Antenna masis were supported on either a tripod or an existing protective post set in concrete near the well. The protective posts were preferred but tripods were used where protective posts were absent. The anchors for the tripods were too shoit for the sandy soil, but by anchoring the ground cable tightiy to the groundrod located directly below the center of the tripod: the tripod was stable. A 1.25-in.-dia, galvanized pipe mast with lightening arrestor groundrod, ground cable, and a coaxial cable leading to an antenna was mounted vertically on top of the tripod or on a well guard post.

The lightning arrestor was mounted on top of the mast, beside the antenna. A grounding cable was attached from the bottom of the mast to the copper groundrod after the groundrod was driven about $5 \mathrm{ft}$ into the ground beneath the center of the tripod or near the well guard post. The lightning arrestor conducts electrostatic discharge directly to earth ground and thus protects the telemetry and datalogger system. A question was raised with the vendor regarding the proximity of the antenna to the lightning arrestor, but assurance was given that the radio was adequately protected.

Each well has one pressure transducer mounted on an in situ calibrator and connected to a datalogger. The datalogger is connected to an FM radio transceiver through an FM modem. A weather shelter was mounted on the pipe mast to enclose the datalogger, FM modem, FM radio, and a small lead-acid battery. A 7-W solar-electric panel with a voltage regulator was mounted on 
the pipe mast and connected to recharge the lead-acid battery. A larger leadacid battery was furnished to supply power during periods of low solar insolation. This battery is enclosed in a separate weather shelter on the pipe mast and is also charged by the solar panel. Up to three wells are monitored by a single datalogger where the wells are close together.

Bending transducer cables too sharply caused changes in datalogger voltratio readings becalize of collapsed air vent tubes in the transducer cables. An approximately 3 -in. radius is the minimum acceptable for the transducer cable. Collapse of the air vent tubes or plugging with debris or water is the most common cause of transducer calibration shift or failure. Transducer cable entry into the datalogger enclosure is important. The ends of the cables and vent tubes must receive air through a desiccant to avoid condensate iormation in the cable and in the vent tubes, especially during late autumn. Desiccators were on the transducer cable ends when received from the vendor. These same desiccators were reinstalled to enclose the vent tube ends after installation in the wells, and additional desiccant packs were placed in the datalogger enclosures. Also, transducer cable entry into the datalogger enclosure, while not sealed air tight, must restrict insects and spiders from entry.

Squelch and volume control settings on the radio are critical to successrul network operation. The squelch was set fully on and the volume control was turned to the $90^{\prime}$ clock position (toward the adjacent connector). If the squelch is only part way on, it can trigger transmission and ultimately discharge the batteries.

The RF modem is identified by unique binary numbers which must be set on the dipswitch before use. Initial identification employed numbers from 101 to 130 (see Table 2.1). Unit 130 was placed on top of the high bay in the 300 Area to operate as the repeater. All stations are called through unit 130 . 
TABLE 2.1 Station Assignment

\begin{tabular}{cl} 
Station & Serving We11 \\
\cline { 2 - 2 } 130 & Repeater \\
129 & $4-9$ \\
128 & SWS-1 \\
127 & $4 B, 4 A, 4 C$ \\
126 & $3 A$ \\
121 & $1 B, 1 C, 1 A$ \\
119 & $3-9$ \\
118 & $18 A, 18 B, 18 C$ \\
117 & $1-10 B$ \\
116 & $16 B$ \\
115 & $5 A, 5 B, 5 C$ \\
113 & $3-12$ \\
112 & $4-7$ \\
111 & $4-1$ \\
109 & $1-8,1-9,1-7$ \\
108 & $8 A$ \\
107 & $7 A, 7 C, 7 B$ \\
106 & $6-1$ \\
102 & $2-1$ \\
101 & $1-1$
\end{tabular}

Transducers were connected to dataloggers according to the following scheme:

$\begin{array}{ll}\text { Wire Color: } & \text { Channel Connection: } \\ \text { Orange } & 1 \text { high } \\ \text { Black } & 1 \text { low } \\ \text { Yellow } & 2 \text { high } \\ \text { Blue } & 2 \text { low } \\ \text { Red } & \text { Excitation } \\ \text { White } & \text { Analog Ground }\end{array}$

Dataloggers were programmed with a keyboard display following installation. The datalogger program configuration is presented in the Appendix. Scan intervals of $1 \mathrm{hr}$ were selected for routine monitoring, except during in situ calibration, when scan intervals were set at $3 \mathrm{~s}$.

\section{In Situ Calibrators}

The in situ calibrator is of two designs. One design consists of two concentric pipes. The inside pipe is $3 / 8,1 / 2$, or $3 / 4 \mathrm{in}$. dia. It is used to suspend the pressure transducer in water. The outside pipe is $1 \mathrm{in}$. dia. It encloses all of the inside pipe in the first design but only two short 
segments of the inside pipe in the second design. The entire assembly in either design is suspended from a mounting bracket located inside the well casing about $1 \mathrm{ft}$ below the top. The transducer is suspended about $1 \mathrm{ft}$ below the lowest expected annual water level in both designs. The transducer cable extends up from the top of the 1/2-in. pipe in both designs and must be looped back down into the top of the well casing to permit spacer insertion during in situ calibration (see Figure 2.3). Stainless-steel pipes at the bottom of the in situ calibrators reach from below the lowest water level to about $1 \mathrm{ft}$ above the highest expected water level. The pressure transducer is suspended from a 1/2-in. pipe by a 3/8-in. tube stainless-steel Swage-lok fitting with Tefion ferrules to apply just enough pressure to prevent cable slippage.

\section{Monitoring System Functional Design and Checkout}

The 300-FF-5 monitoring system was designed to measure and store waterlevel and temperature data at the wellhead and to deliver the data on demand by radio telemetry to a central computer for processing and storage. The functional checkout consisted of the following steps:

1. check equipment descriptionsi against specifications

2. test transducer accuracy, precision, bias, and hysteresis

3. test datalogger for resolution, precision, bias, and stability

4. test radio for frequenc', power, and reflectance with antenna

5. test components together to ensure system compatibility.

\subsubsection{System Calibration In the Field}

This procedure for in situ calibration was developed to minimize effects of time-variant-water-level changes in the aquifer by running the calibration no more than $15 \mathrm{~min}$. The calibration time may vary from well to well, depending on the recovery rate of the we11, but need $n$ nt exceed 15 min. A scan rate of $3 \mathrm{~s}$ was selected to collect a statistically significant number of data points beyond recovery for valid data processing at the $1 \%$ confidence level. Twenty "undisturbed" data points were selected for each of three calibration positions. The first position is the normal resting position, the second 


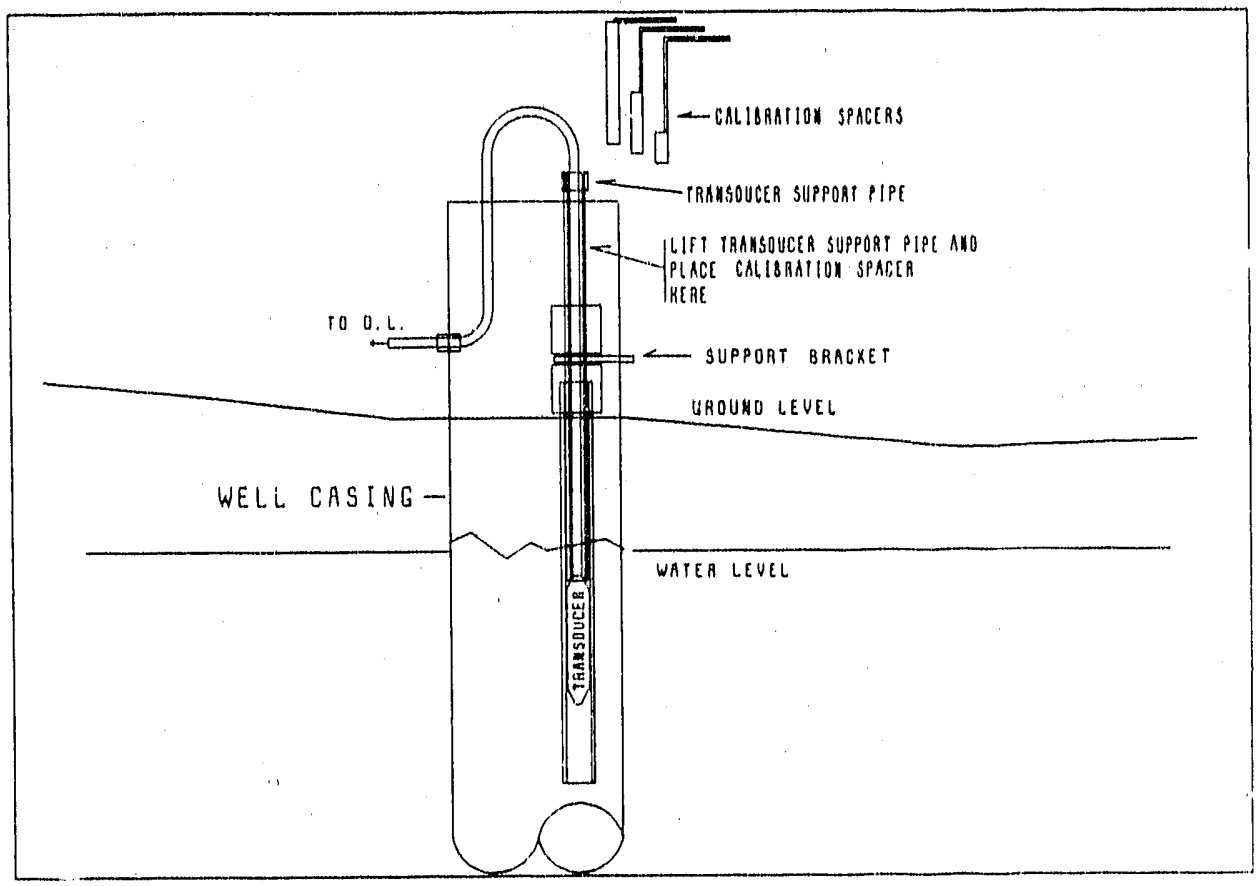

FIGURE 2.3. In Situ Calibrator for Pressure Transducers, to be Used with Standard Spacers for Calibration in Place

position is a vertically displaced position (using the spacer bar), and the third position is the original posttion. Selection of 20 data points for each position during in situ calibration facilitated data processing. A routine procedure for preparation and calibration for each well was followed for consistent results.

\section{Preparation and Displacement for Calibration}

A routine preparation and calibration must be followed for consistent results. The following procedure yielded adequate results:

1. Remove well cap and pull coiled transducer cable free. Do not touch or disturb the transducer cable in any way during calibration data collection.

2. Unlock and open datalogger enclosure and attach readout device to datalogger.

3. Reset scan time to $3-\mathrm{s}$ interval and monitor transducer reading.

4. Take a water-level measurement with a steel tape and record it with a corresponding transducer reading. 
5. Allow datalogger to record 20 undisturbed water-level readings.

6. Lift the transducer suspension pipe assembly with a steel rod hooking tool and insert the standard spacer bar.

7. Log readings unt 1120 readings are recorded beyond well recovery. (As few as 30 readings and as many as 100 readings were enough on we $11 \mathrm{~s}$ PNL staff tested. If well recovery is incomplete, increase the number of readings as necessary.)

8. Remove the standard spacer, and lower the transducer support pipe to tts ortginal support position.

9. Log the same number of readings as in step 6 .

10. Reset scan time to 3600 seconds (1 hr).

11. Remove readout device from datalogger.

12. Close datalogger enclosure, coll transducer cable into well, and cover well.

\section{Data Retrieval and Analys is}

A computer with software support at the base station was used to prompt the monitoring station for data transmission. Data was transmitted directly to the base station or indirectly via the repeater on top of the high bay. The telecommunications software was set to append the transmitted data to an ASCII file designated for each monitoring station. The ASCII file was imported into Quattro Pro and Lotus spreadsheet programs for processing and analysis. Only Quattro Pro is documented here.

These instructions are for processing in situ calibration data. NOTE: All filenames in these instructions have the extension WQ1 for Quattro Pro processing.

\section{Setting Up Data File Format}

1. Transmit data from the monitoring station. The data file should be an ASCII file.

2. In Quattro Pro, import the data flle into the spreadsheet. Press /TIC $\langle$ filename $\rangle$ returri

3. Strip the data file of unnecessary data by deleting columns and rows. Press /EDC <return> to delete columns. Press /EDR <return> to delete rows. Use the '.' and arrow keys to enter the block of rows or columns to delete before pressing <return>. 
4. Move cursor to cell A1, the home position, and insert nine empty rows. Press /EIR <down arrow key eight times> <return>

5. Move cursor to columin $C$ insert one empty column. Press / EIC <return>

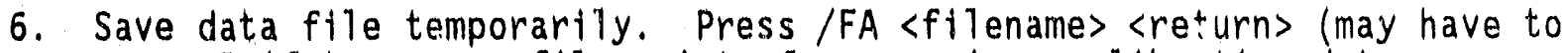
press $R$ if temporary file exists from prevtous caltbration data processing). Identify these filenames with the station number and that it will be for temporary use only ( $0.9 .$, 129TEMP).

7. Frase spreadsheet by pressing /FE.

8. Retrieve master file, which is identified by station number followed by 'MAST' (e.g., 129MAST), into the spreadsheet by pressing /FR <filerame> $\langle$ return>.

9. Combine the temporary data file with the master file by pressing /TCCF <temporary filename> <return>. Make sure the cursor is in cell Al before combining files. The day of year, time, and data values should appear in the spreadsheet under the corresponding table headings in the master file.

10. Before doing any further processing, save the combined files as one file. This processing file should be identified by the station number, day of year caltbration was run, and year (e.g., calibration run on 15 Aug 1991 at station 129 would be named 12922791).

\section{Data Processing and Refinement}

1. Move cursor to bottom of data file and delete extra rows provided by the master file. The number of data values should be equal to or less than the number of rows provided by the master file for all data to be processed. Press /EDR <'.' and arrow keys to select block of rows $>$ <return>.

2. Adjust number of entries in columns labeled "Normal Position" and "Displaced 1 Foot" to correspond with the normal position data values and displaced position data values in the raw data column. For a $1-\mathrm{ft}$ displacement, the normal position values are approximately 1.1 volt ratio greater than the displaced position values. This will require copying formulas from a cell to a block and erasing unnecessary blocks.

a. To copy, move cursor to cell to copy from and press /EC <return>, then use '.' and arrow keys to select block to copy to.

b. To erase, move cursor on first cell of block to erase and press /EE and use arrow keys to select block.

3. Display prestructured graph for viewing raw data to select which data values to process. Press /GND and select graph name that has "VR" in 
it. Extend 1st, 2nd, and $X$-axis series to the end of the data file by entering the SERIES menu (Press/GS) and using the arrow keys.

4. Select the $Y$-axis range (Low and High) for the normal position values by entering the $Y$-AXIS menu (Press /GY). Select the 2 nd $Y$-axis range for the displaced position values in the Y-AXIS menu (Press/GY2). The $Y$-axis and 2 nd $Y$-axis scales must be proportional. View the graph by pressing/GV or F10.

5. Enter the graph labels (Press/GT) and edtt the graph using the annotator (Press /GA) (see Quattro Pro manusl for operating the annotator).

6. Name the graph (for future use) by pressing / GNC <name of graph>.

7. Examine the data on the graph and select 20 consecutive data values, excluding outliers, from the normal position before displacement, during displacement, and the normal position after displacement. Select from the portion of the data that exhibits stable readings, that is, equilibration from water-level recovery due to displacement by the transducer and pipe column.

8. Copy the 60 data values and corresponding day of year, time, and data point number to the corresponding columns in the calculations block.

9. Run the linear regression utility on the selected data values (Press (TARG). Before pressing $G$, make sure that the blocks under the headings "Data Point Number" and "Normal Position Values for Regression" in the calculations block have been selected for the independent and dependent variables, respectively. Also make sure the output is a block just below the columns of data that are regressed.

10. The calibration factor will be calculated automatically. The calibration factor ranges from 0.90 to $0.94 \mathrm{ft} /$ volt-ratio for the transducers tested on this project.

\section{Display Final Graph}

1. Display the prestructured graph by pressing /GND <name of graph with "FT" in $|t\rangle\langle$ return>.

2. In the SERIES menu, select the normal position values in feet, displaced position values in feet, and the generated values for the slope in feet for the 1st, 2nd, and 3rd series, respectively. Select the data point numbers as the $X$-axis series.

3. Enter the $Y$-axis range (Low and High) in the $Y$-AXIS menu.

4. Edit the graph labels in the TEXT menu.

5. Edit or enter labels for the graph, as needed, by using the annotator (Press /GA). 
6. Name the graph for future use by pressing / GNC <name of graph> <return>.

7. Resave the processed data file by pressing/FAR.

\section{Calibration Factor}

The calibration factor range mentioned in item 10 of the Data Processing and Refinement section may be used to obtain transducer displacement below the liquid surface. When corresponding steel tape and pressure transducer readings are available, the transducer reading converted to depth may be assigned the depth value obtained from the steel tape. Changes in pressure transducer readings, multiplied by the calibration factor and added algebraically to the initial reading, yield new water depths that should agree with stee 1 -tape readings within $\pm 0.01 \mathrm{ft}$. 


\subsection{RESULTS AND DISCUSSION}

Water depths were measured within $\pm 0.01 \mathrm{ft}$ and transferred by radio telemetry into a database. However, some measurements were outside specified tolerance limits. These exceptions and their significance are discussed under the appropriate headings.

\subsection{EOUIPMENT OPERATIONAL CHECKOUT}

A11 equipment functioned as received, but some system components required significant adjustments to make them suitable. Antennas were incorrect and unusable for the specified frequency, for example, because they caused too much reflectance. They were returned to the vendor and replaced with the specified equipment, while radios were adjusted at PNL.

\subsubsection{Radio System Test Results}

Twenty-eight of 30 radios received were acceptable without adjustment. Two required adjustment to comply with specifications. All radios responded to calls from the computer connected to the base station. All communications links worked in the laboratory. Uniqueness of call identification was checked. Each system responded only to its call number. All systems demonstrated acceptable store-and-forward operation--used to link remote radios to the base station through other radios located between them.

\subsubsection{Datalogger Test Results}

\section{Comparison with Standard Multimeter}

Datalogger voltage measurements compared favorably with calibrated microvoltmeter readings over all five ranges. Although differences existed, they were attributed to both the multimeter and the datalogger. Dataloggers measured voltages specified for each range. Table 3.1 shows test results from 20 dataloggers.

\section{Results of Resolution Tests}

Resolution was about twice as good as the $0.6 \mu \mathrm{V}$ specified and sufficiently stable over time. Figure 3.1 shows an example of the deviations from precisely divided voltages due to datalogger resolution insensitivity. 
TABLE 3.1. Fraction of Specified Tolerance that Each Station Reading Deviated from Its Expected Reading in Each Range (equipment as received from vendor)

\begin{tabular}{|c|c|c|c|c|c|}
\hline \multirow[b]{2}{*}{ Station } & \multicolumn{5}{|c|}{ Range } \\
\hline & 1 & 2 & 3 & 4 & 5 \\
\hline 106 & 0.800 & 1.281 & 0.459 & 0.326 & 0.092 \\
\hline 107 & 0.323 & 0.248 & -0.186 & 0.003 & -0.174 \\
\hline 108 & 0.203 & 0.295 & -0.305 & -0.092 & -0.000 \\
\hline 109 & -0.593 & -0.335 & -0.267 & -0.298 & 0.063 \\
\hline 110 & 0.298 & -0.166 & 0.122 & -0.087 & 0.017 \\
\hline 111 & 0.166 & 0.257 & 0.324 & 0.448 & 0.004 \\
\hline 112 & 0.974 & 1.065 & 0.965 & 0.692 & 0.012 \\
\hline 113 & 0.681 & 0.495 & 0.506 & 0.412 & 0.067 \\
\hline 114 & 0.206 & -0.202 & -0.135 & 0.001 & -0.024 \\
\hline 115 & -0.089 & -0.108 & 0.402 & 0.142 & 0.007 \\
\hline 116 & -0.080 & -0.210 & 0.078 & .0 .087 & -0.065 \\
\hline 120 & -1.373 & -1.004 & -0.714 & -0.360 & 0.056 \\
\hline 121 & -0.328 & -0.070 & 0.163 & -0.034 & 0.022 \\
\hline 122 & -0.736 & -0.756 & -0.579 & -0.788 & 0.180 \\
\hline 123 & -0.314 & -0.333 & -0.321 & -0.236 & -0.031 \\
\hline 124 & -0.261 & -0.726 & -0.604 & -0.377 & 0.088 \\
\hline 125 & 0.756 & 0.515 & 0.415 & 0.180 & 0.010 \\
\hline 126 & 0.654 & 0.245 & 0.311 & 0.076 & -0.216 \\
\hline 127 & -1.114 & -0.300 & -0.290 & 0.052 & 0.014 \\
\hline 128 & -0.171 & -0.190 & -0.346 & -0.145 & 0.061 \\
\hline
\end{tabular}

\section{Volt-Ratio Processing to Avoid Errors}

One system test assessed changes in pressure transducer readings resulting from excitation voltage changes. Excitation voltage varied from about 1.34 to $2.5 \mathrm{~V}$ with no perceptible change in datalogger output readings. This result was possible because the readout was always produced as the ratio of output to excitation vortage. Thus, when excitation voltage varied, output voltage varied proportionally--a highly desirable characteristic in a datalogging system. This result is possible only when instrument stability is adequate. 


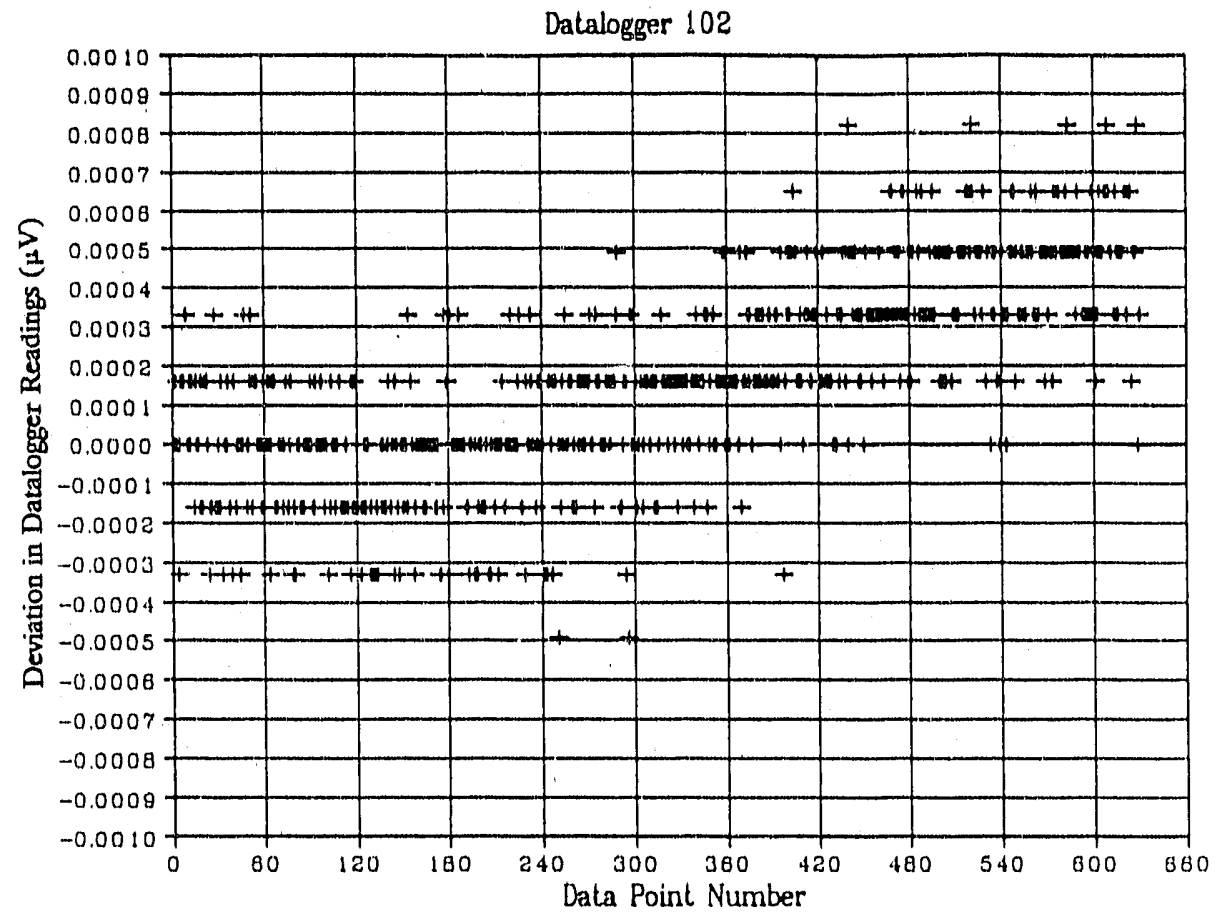

FIGURE 3.1. Datalogger Resolution in Response to 11 Changes in Voltage of 0.1 Microvolt Each

\subsubsection{Water Column Transducer Test Results}

Two types of transducer tests demonstrated that the pressure transducers were capable of both precise and wide-range measurements. While both of these tests relied on a water column, they were very different in application.

\section{Results from Wide-Range, Preinstallation Tests}

The wide-range tests demonstrated excellent transducer precision, but the non-linearity over $15 \mathrm{ft}$ of head was as much as $0.04 \mathrm{ft}$ (Figure 3.2). The manufacturer did not apply accuracy tolerance outside the specified transducer range. Thus, the 1 psig transducers had no accuracy specified in over-range mode. Nevertheless, all of the pressure transducers tested in the sample demonstrated adequate over-range capability with acceptabie linearity for the expected range of use. 


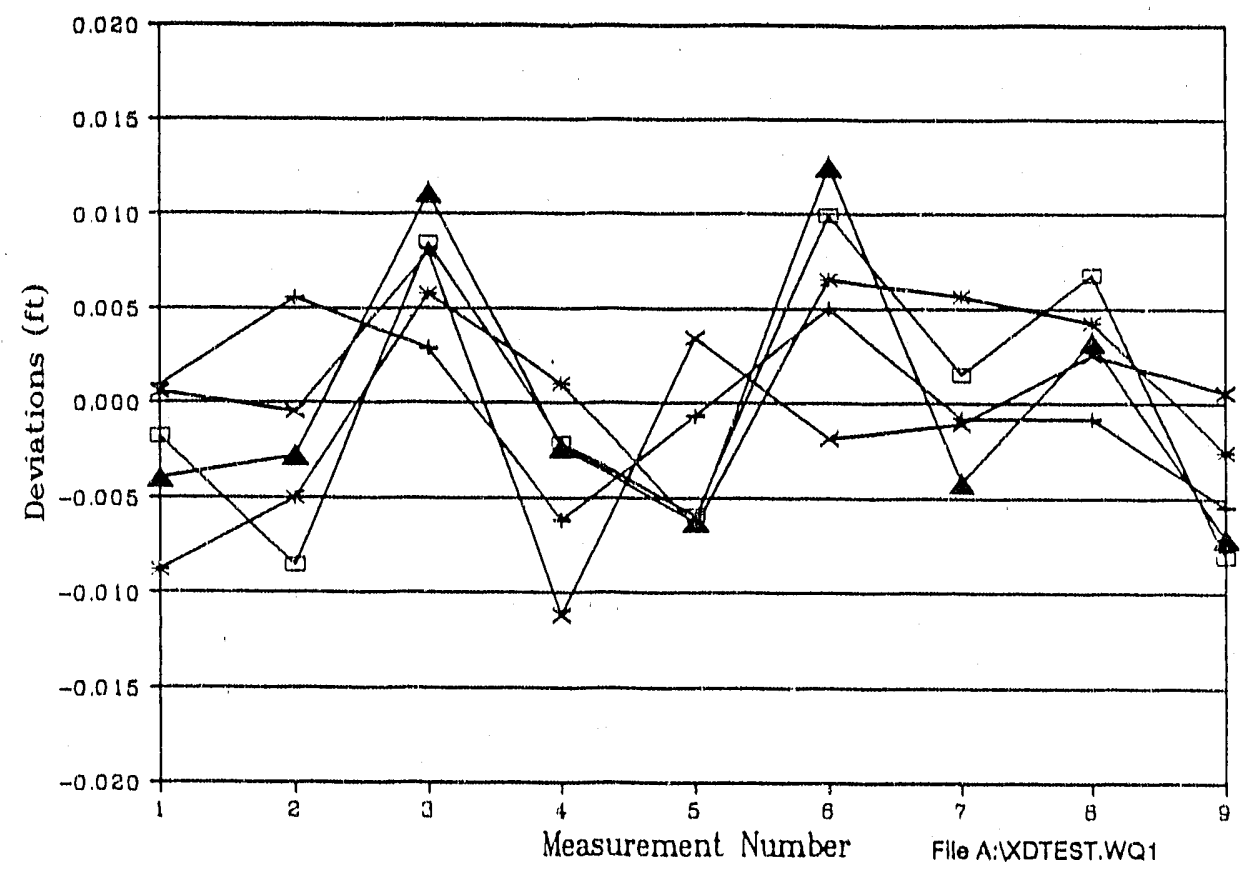

$+1 * 2 \times 5$
$E-3 \times 2$

EIGURE 3.2. Wide-Range Calibration Test Results, Showing Pressure Transducer Deviations from Steel-Tape Readings When Transducers Were Tested in Over-Range Conditions

\section{Results from Narrow-Range, Preinstallation Tests}

Narrow-range tests revealed that 11 of 54 transducers were within a tolerance of $\pm 0.0025 \mathrm{ft}$. The 43 out of tolerance were consistent in deviation pattern and stable. A11 demonstrated capability to measure water levels within $\pm 0.01 \mathrm{ft}$. Only 11 were four times that good, as required by current $Q A$ standards. Because a11 were an oil immersion type with a titanium diaphragm and all were stable throughout the tests and no brand had proven equal or better, the decision was made to accept these pressure transducers as state of the art.

Figure 3.3 shows examples of calibration results from two transducers, identified by SN400808 and SN409776, that are typical of the best and poorest quality, respectively. The measurement number represents the depth position of the transducers, beginning at 0 for measurement number 1 , increasing in 0.5 -ft incremerits to measurement number 6 , and then ending at depth position 0 


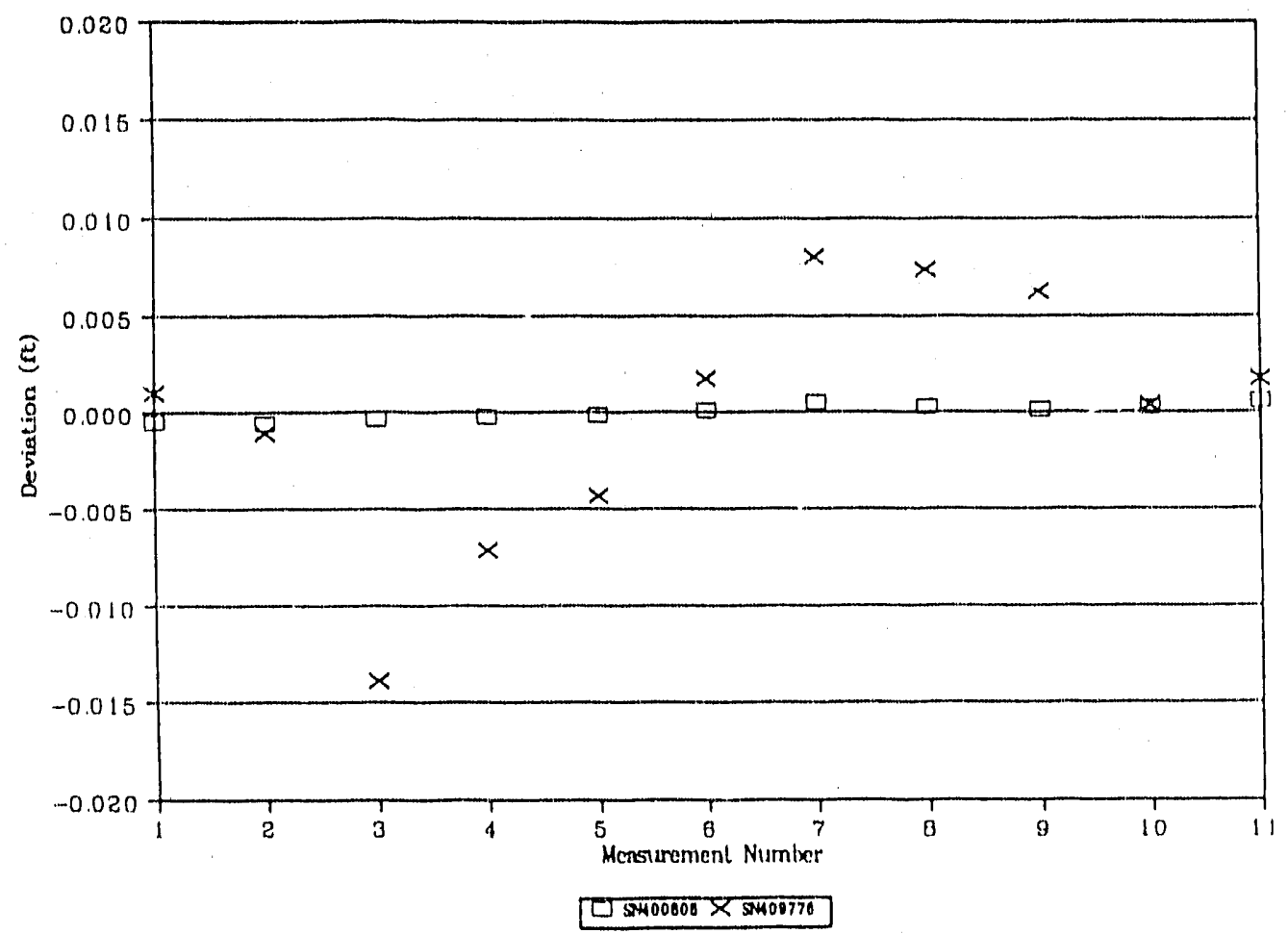

FIGURE 3.3. Results from Calibration of Pressure Transducers SN400808 and SN409776 in a Standard Barrel

for measurement number 11. Results indicate that transducer SN400808 is within $\pm 0.0025 \mathrm{ft}$ and that transducer SN409776 is within $\pm 0.01 \mathrm{ft}$ during the emergence half of the cycle. These two transducers were calibrated during the same calibration run and thus represent the difference between transducers rather than a difference in treatment during calibration.

The deviation pattern represented by each of the transducers in Figure 2.3, that is, negative deviation in the downward direction and positive deviation in the upward direction, is hysteresis and was a characteristic pattern of all the transducers calibrated.

\subsection{COMMENTS ON INSTALLATION WITH RESULTS FROM FIELD TESTS}

Monitoring system assembly and checkout at each well was followed by in situ calibration. Prestructured programs were prepared to process the data collected during field calibration. Each of these three facets of the work are discussed. 


\subsubsection{Results and Conclusions from System Functional Checkout}

A11 systems functioned acceptably. Unique system identifiers allowed systems to operate only when correctly called. Radio telemetry worked better than expected. Al1 stations responded through the repeater, and all but one station responded without the repeater, regardless of the 1 ine-of-sight status. Al1 dataloggers operated for a 11 laboratory tests and all field tests on the first eight wells. The base station performed correctly, even without a line-of-sight access. All field data, including in situ calibrations, have been recovered without difficulty by radio telemetry.

\subsubsection{Field Cálibration Results}

Figures 3.4 through 3.11 show results of in situ calibration for the first eight wells monitored (data for remaining wells are incomplete at this writing). Table 3.2 shows the calibration factors obtained during all of the in situ calibration runs, including the average and standard deviation for each wel1. The average calibration factor ranged between $0.9057 \mathrm{ft} / \mathrm{V}$ ratio and $0.9279 \mathrm{ft} / \mathrm{V}$ ratio, which is in the range expected for these types of transducers. The low values for standard deviation suggest that the procedure developed for performing in situ calibration is consistent in determining calibration factors. The procedure is adequate because the results are not influenced by natural water-level changes in the aquifer and the procedure accounts for water-level recovery due to displacement by the transducer and pipe assembly.

One comprehensive example of in situ calibration and data processing results is shown in Figure 3.6 for we11 399-1-16B. Data points 1 through 86 represent the normal resting position before displacement, data points 89 through 232 represent a displacement of $1 \mathrm{ft}$, and data points 236 through 395 represent the original resting position after displacement of the transducer. We adjusted points 89 through 232 by $1 \mathrm{ft}$ so we could see the deviations instead of just the $1-\mathrm{ft}$ displacement in the data. Intervening data points are not shown on the graph. Each data point represents a 3 -s interval. 


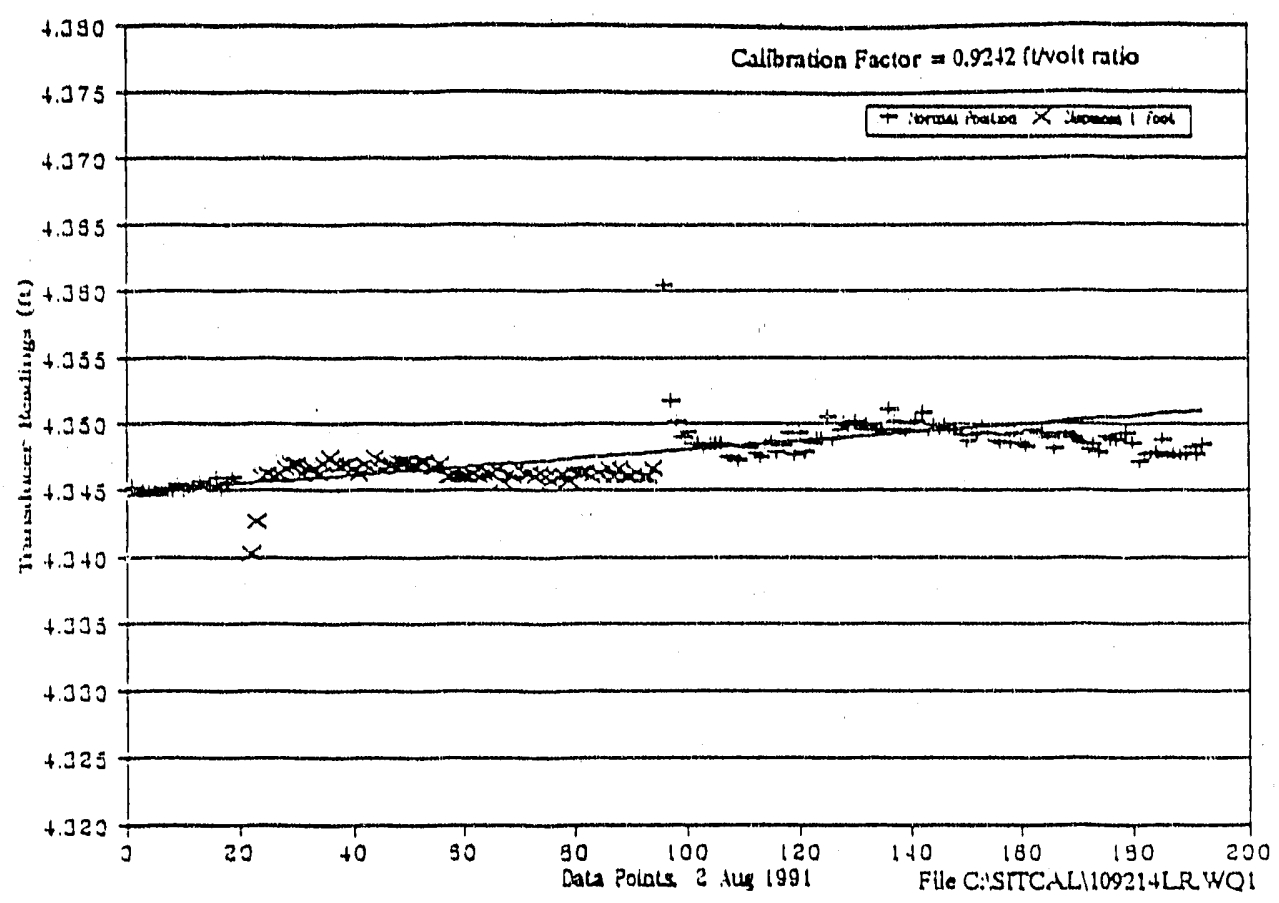

FIGURE 3.4. Results of In Situ Calibration for Wel1 399-1-8 on Day 214, 1991

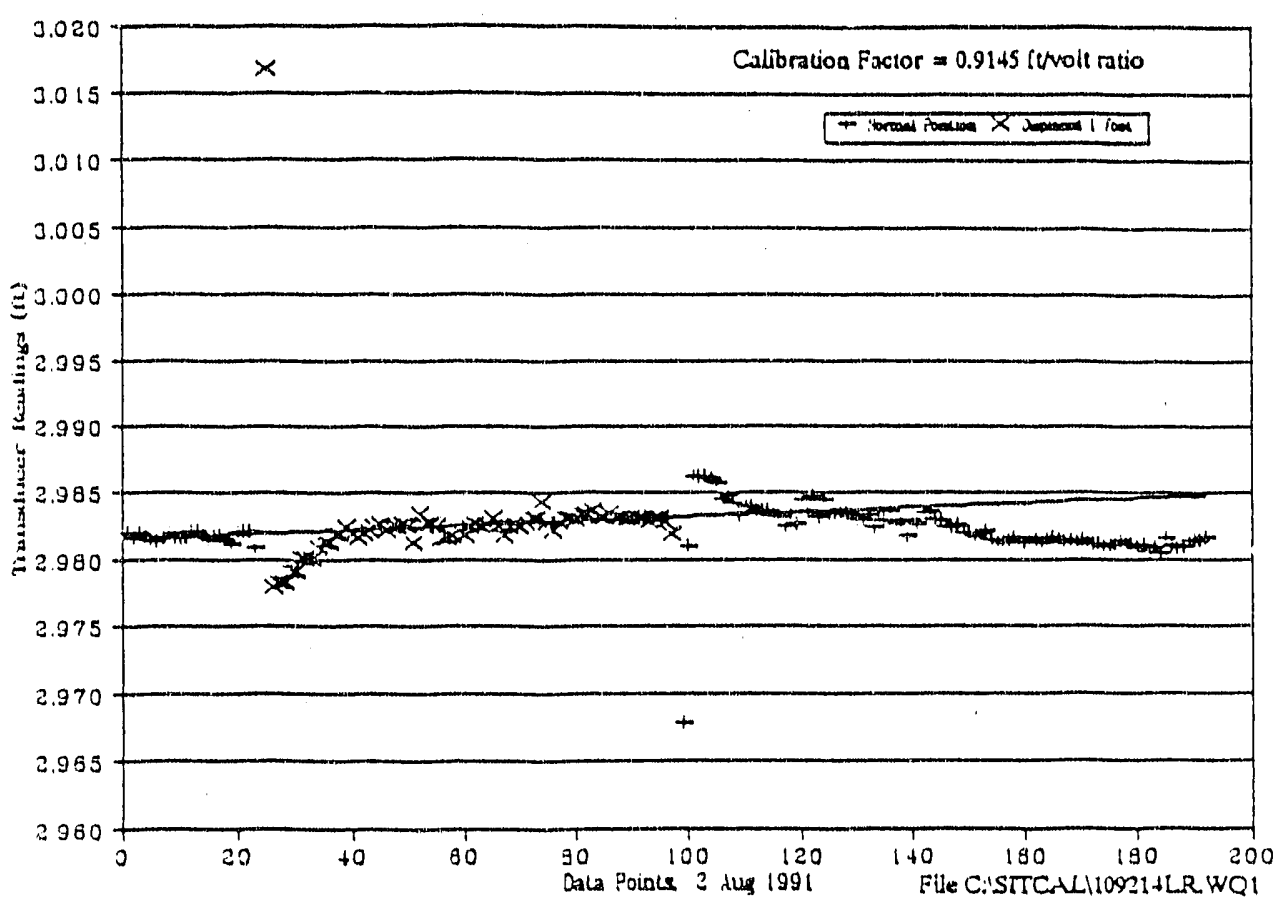

FIGURE 3.5. Results of In Situ Calibration for Wel1 399-1-9 on Day 214, 1991 


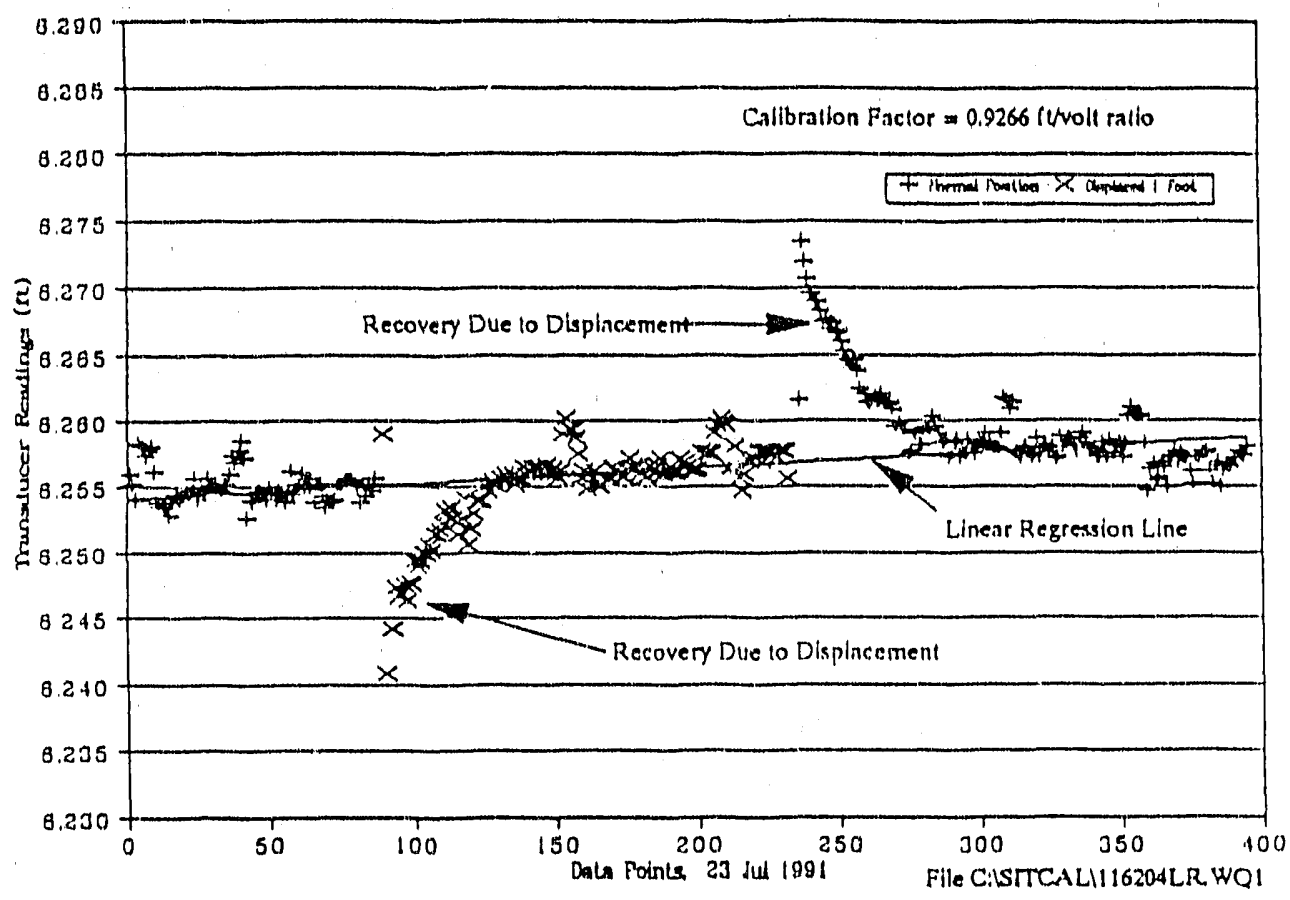

FIGURE 3.6. Results of In Situ Calibration for We11 399-1-16B on Day 204, 1991

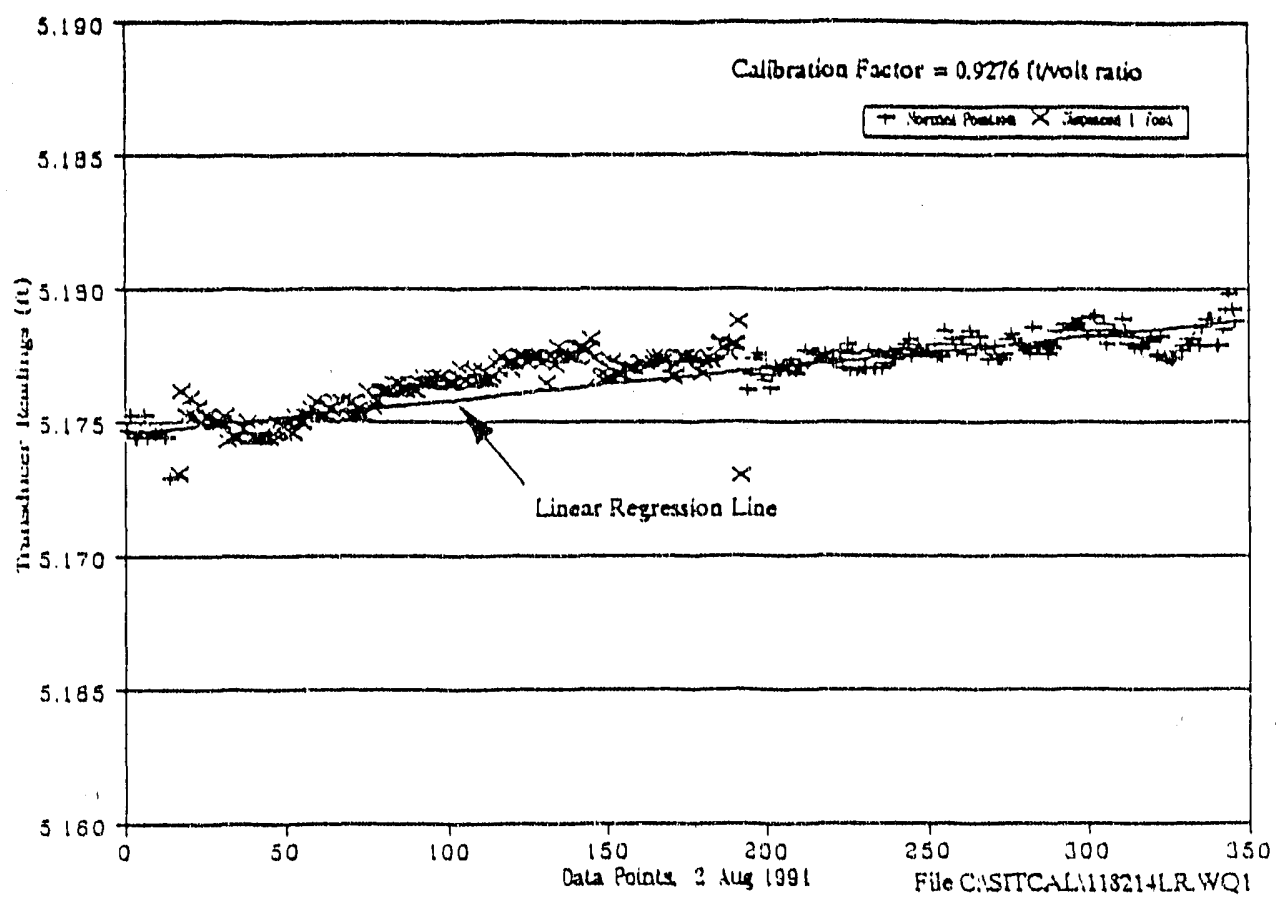

FIGURE 3.7. Results of In Situ Calibration for We11 399-1-18A on Day 214, 1991 


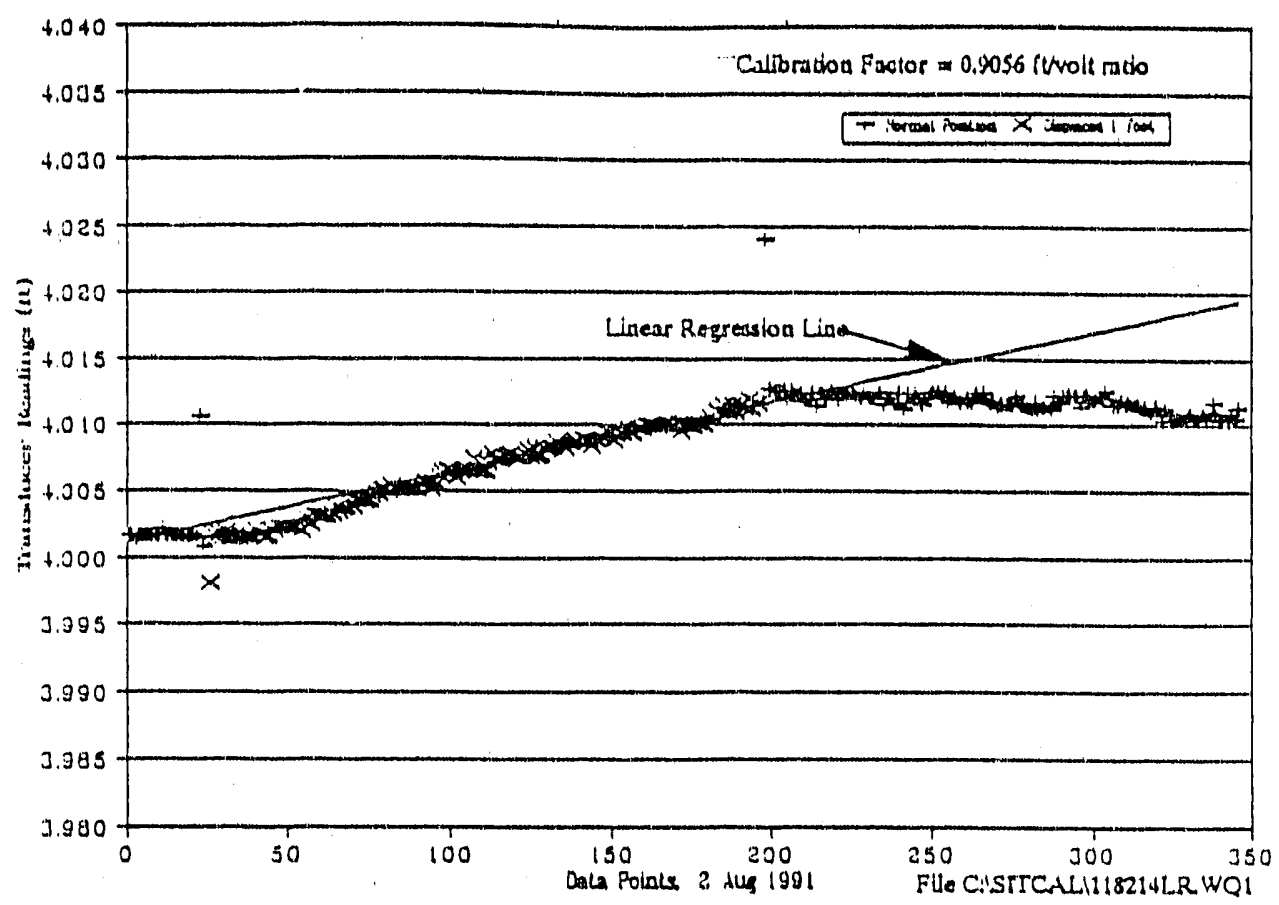

FIGURE 3.8. Results of In Situ Caltbration for Well 399-1-18B on Day 214, 1991

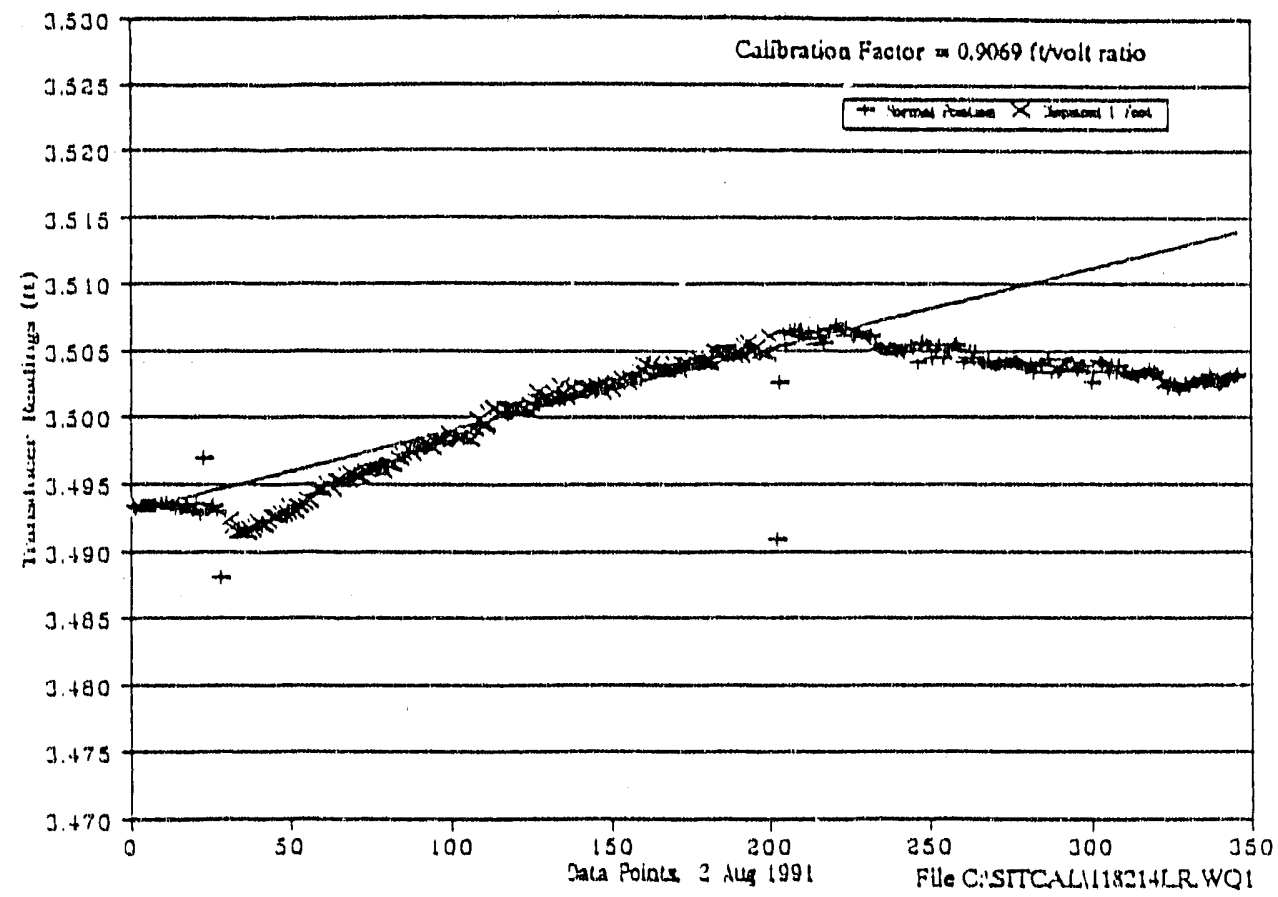

FIGURE 3.9. Results of In Situ Calibration for Well 399-1-18C on Day 214, 1991 


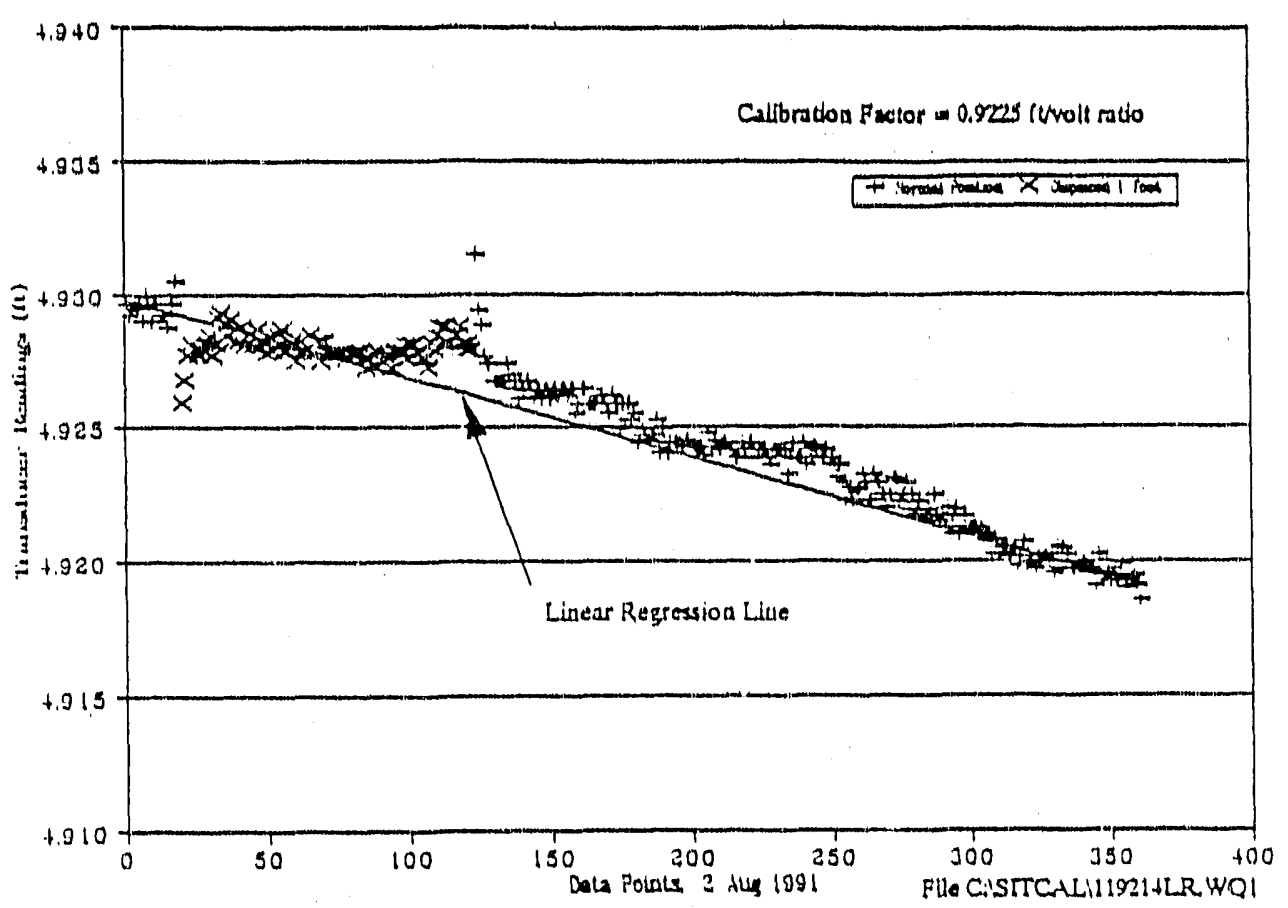

FIGURE 3.10. Results of In Sttu Calibration for Well 399-3-9 on Day 214,1991

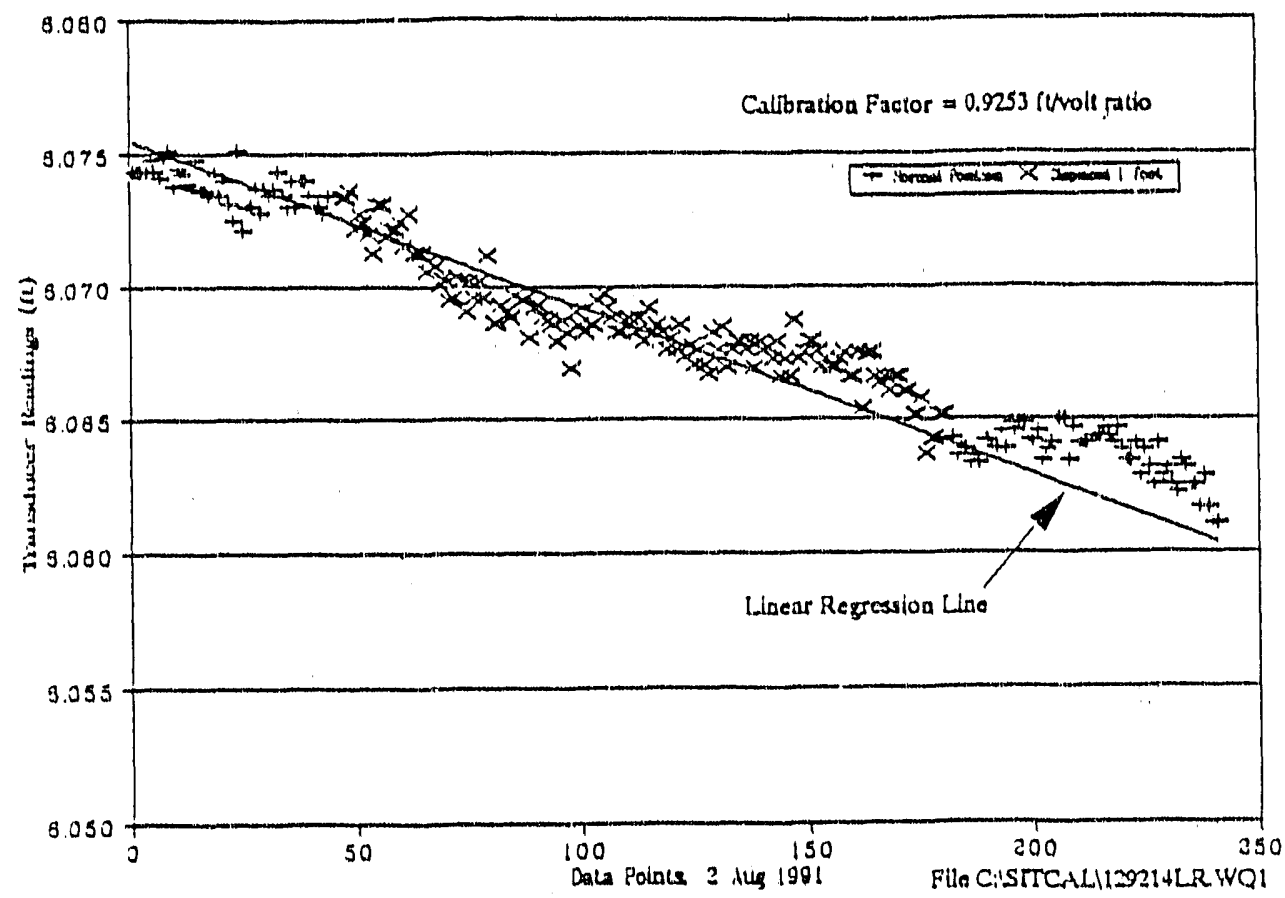

FIGURE 3.11. Results of In Situ Calibration for Well 399-4-9 on Day 214,1991 


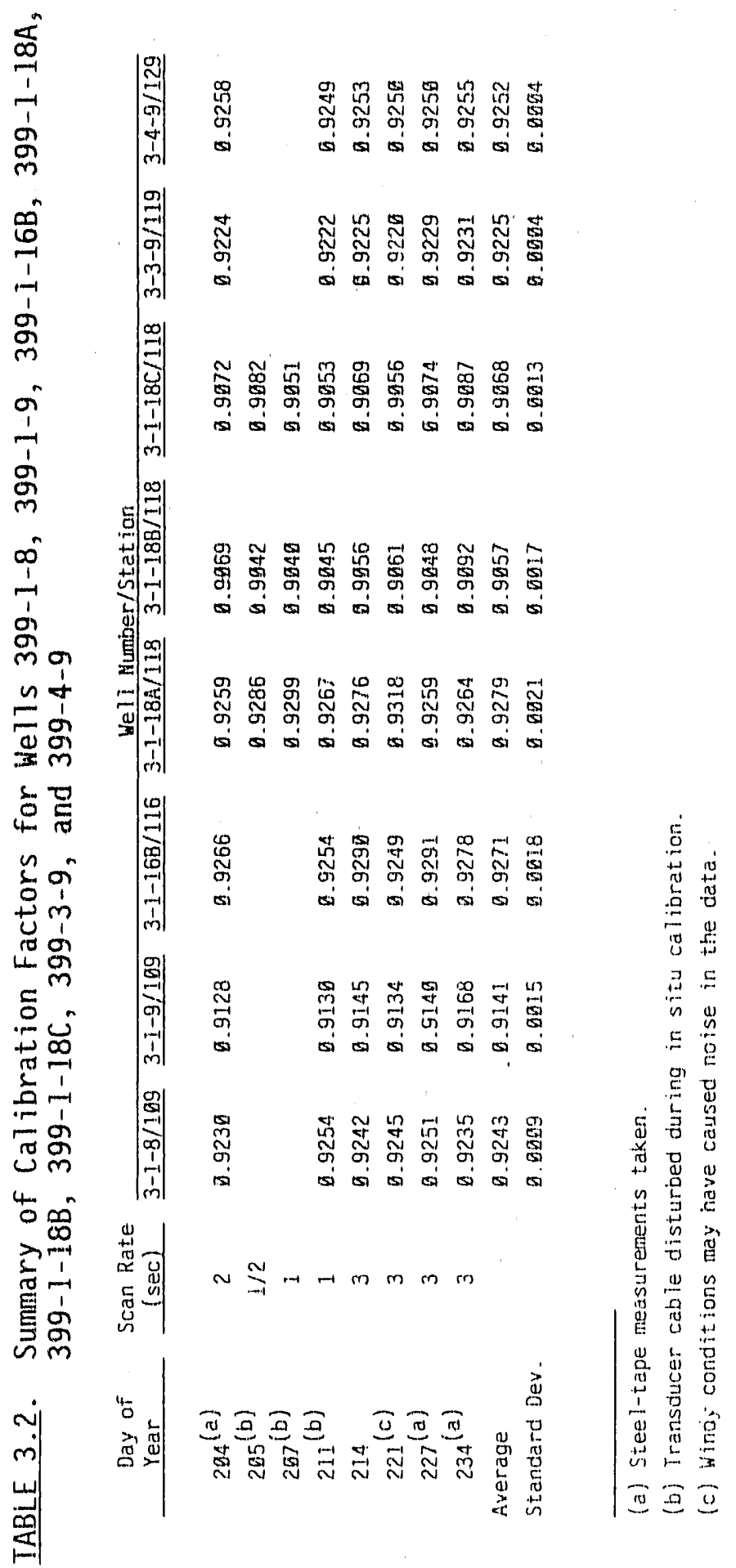


The graph fllustraces the problems assoclated with water-level changes mentioned above. The graph shows that well recovery from water-level displacement, which occurred after the transducer was ratsed and lowered, is superimposed on the net water-level change that occurred in the aquifer during the caltbration run. The linear regression line indicates that the average water level rose approximately $0.005 \mathrm{ft}$ during the caltbration run. The three sets of 20 data points each were taken from the data potnts after well recovery was complete.

Calibration cross-check with steel tape revealed the need to conftrm steel-tape readings by replication, even though all our readings were taken by one properly tratned person. For example, Figure 3.12 shows devtations of the transducer readings from the stee1-tape measurements. A1l but three points close1y agree. The three large deviations occurred on day 227. Stee1-tape measurements were taken during the in situ caltbration interval, immediately before the transducer was displaced. Among six in situ caltbrations on each

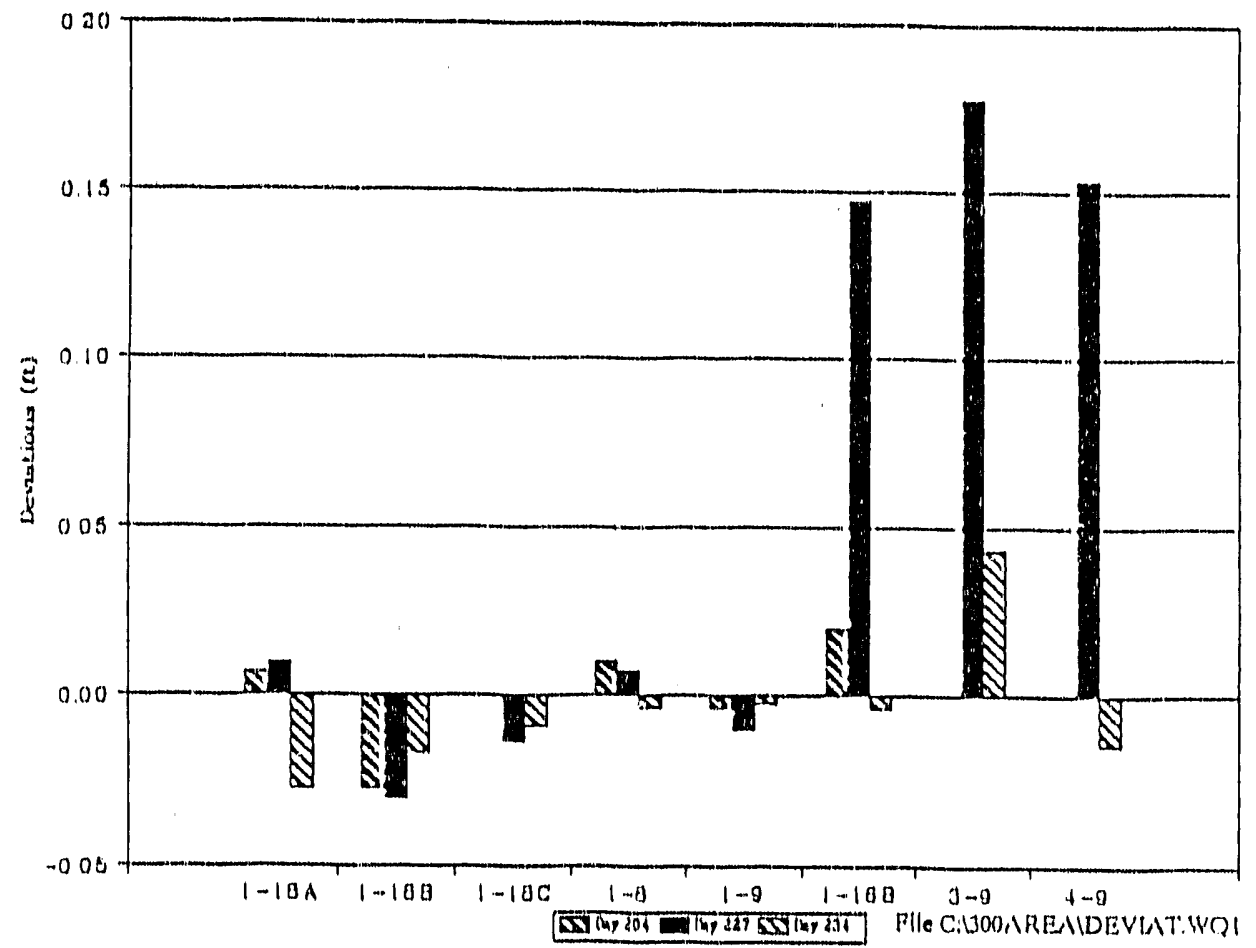

EIGURE 3.12. Deviations of Transducer Measurements from Corresponding Stee T-Tape Measurements 
of the three transclucers in question, the maximum standard deviation was 0.0018 . Also from Table 3.2, a maximum error of 0.006 tit is indicated by the in situ caltbration, thus leading us to conclude that three of the steel-tape readings were in error. Significantly, the three errors are stmilar in magnitude and direction. Previous and subsequent steel-tape measurements agree with the transducer measurements.

\subsubsection{Use of Prestructured Processing and Data Ftles}

The prestructured spreadsheet master flles were combined with the raw data flles to obtain analyses of the calibration data. These prestructured fites greatly reduced the time required to process calturation data to calculate the calibration factors. They also eliminated computational errors and maintained computational consistency, once they were thoroughly tested and checked.

Figure 3.13 shows the layout of the prestructured processing and data flle for transducer calfbration in the standard barre1. Figure 3.13a shows the flle structure format as it looks before data processing, showing the file headings and the calculation steps. Figure 3.13 b shows an example of a file after it is combined with the preformatted raw data flle, showing the file headings, raw data, and calculation results.

Figure 3.14 shows the layout of the prestructured processing and data flle for in situ transducer caltbration. Figure 3.14 a shows the structure format of the master flle prtor to data processing, showing the file headings, summary of calculations, and the calculation steps. Figure $3.14 b$ shows an example of a file after it is combined with the preformatted raw data file, showing, in addition to the headings and summary of calculations, the raw data, the calculation results, and the calibration factor.

\subsubsection{Fteld Measurements}

Figures 3.15 through 3.22 show well water level depths below the tops of the well casings. Al1 but the three readings discussed above agree. Apparently, the water fluctuation ranged above $3 \mathrm{ft}$ during the period of measurement. We11 399-1-9 evidently represents a different aquifer, as evidenced by time and magnitude of change. 


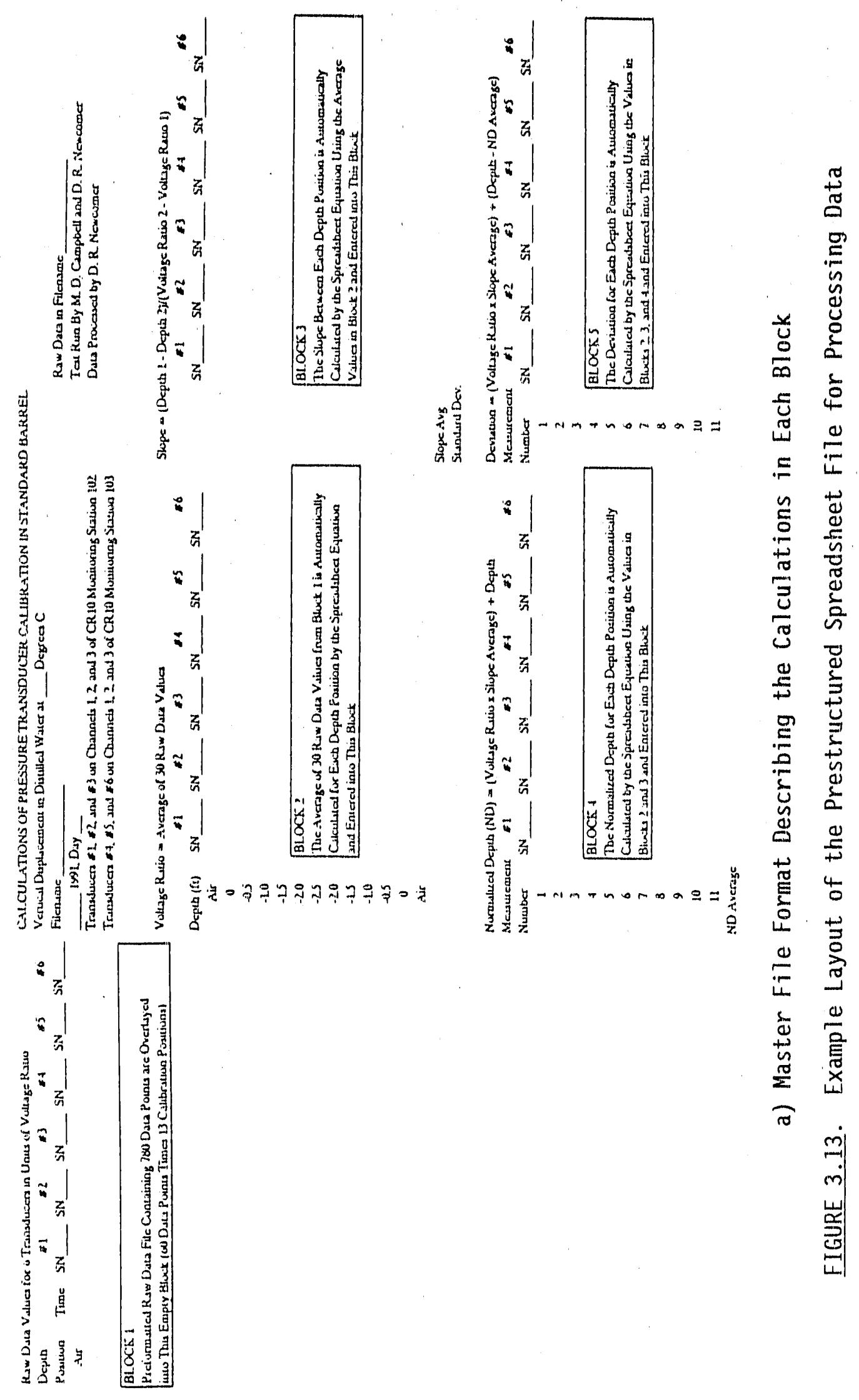




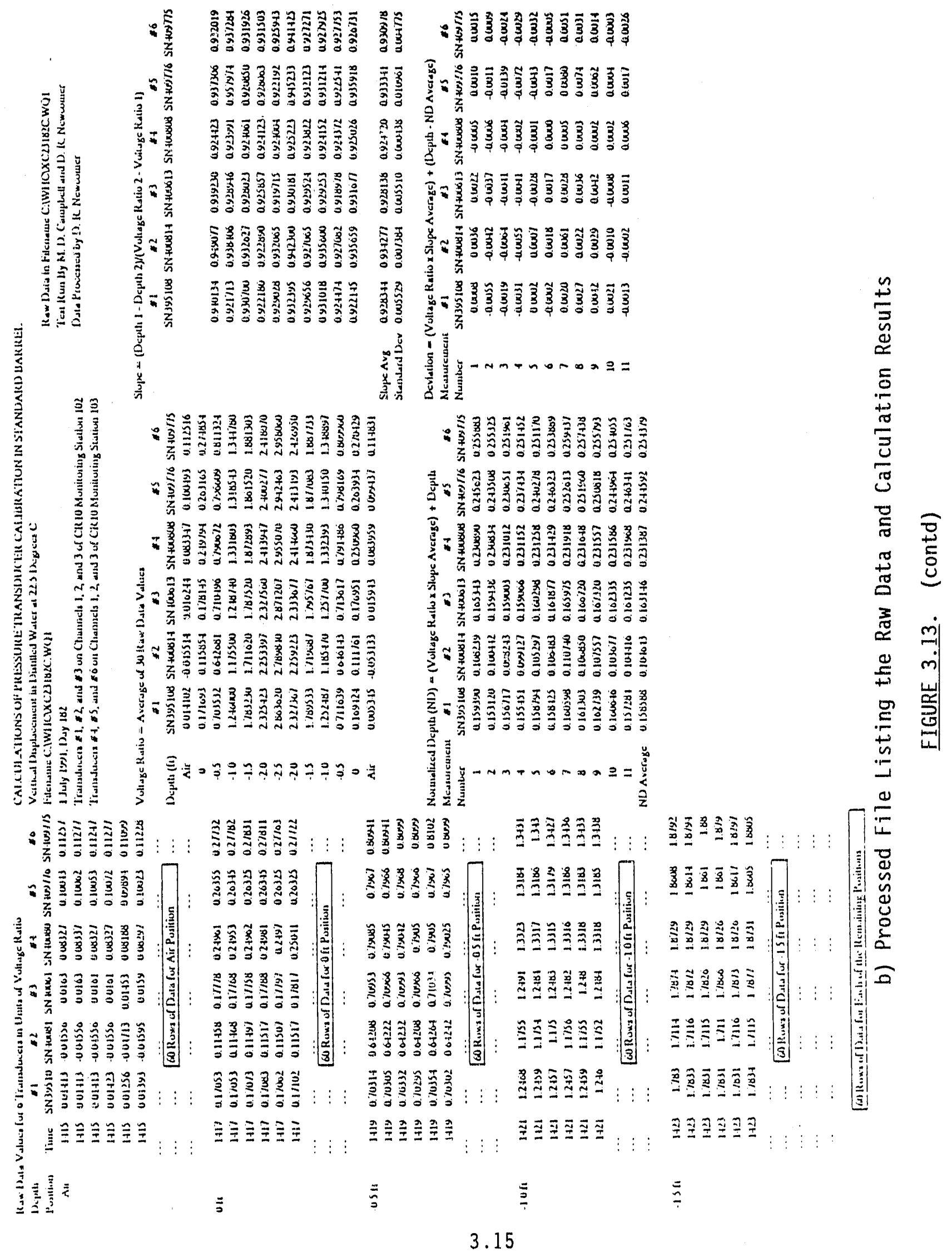




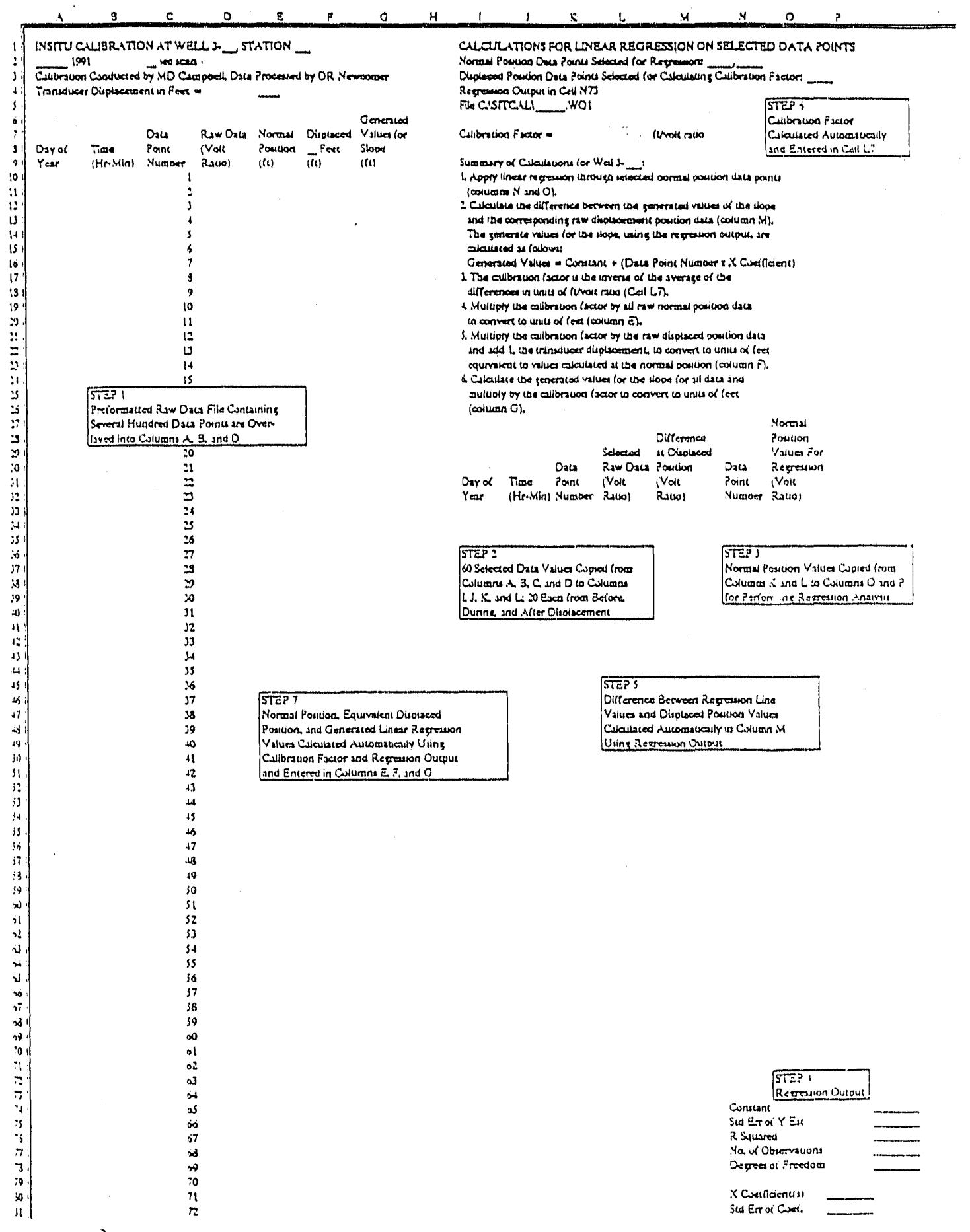

a) Master File Format Describing the Calculation Steps

FIGURE 3.14. Example Layout of the Prestructured Spreadsheet File for Processing In Situ Calibration Data 


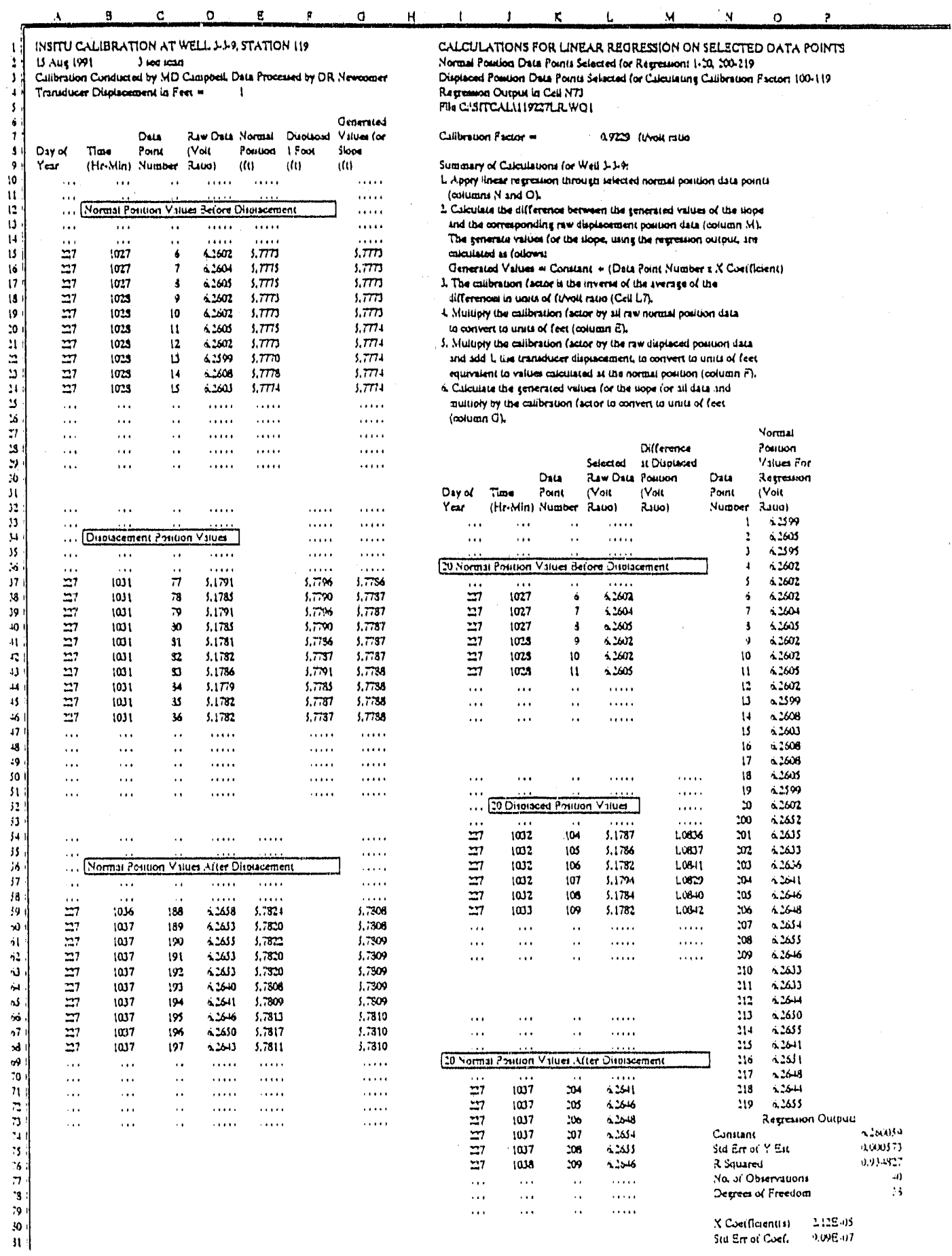

b) Processed File Listing the Raw Data and Calculations

EIGURE 3.14. (contd) 


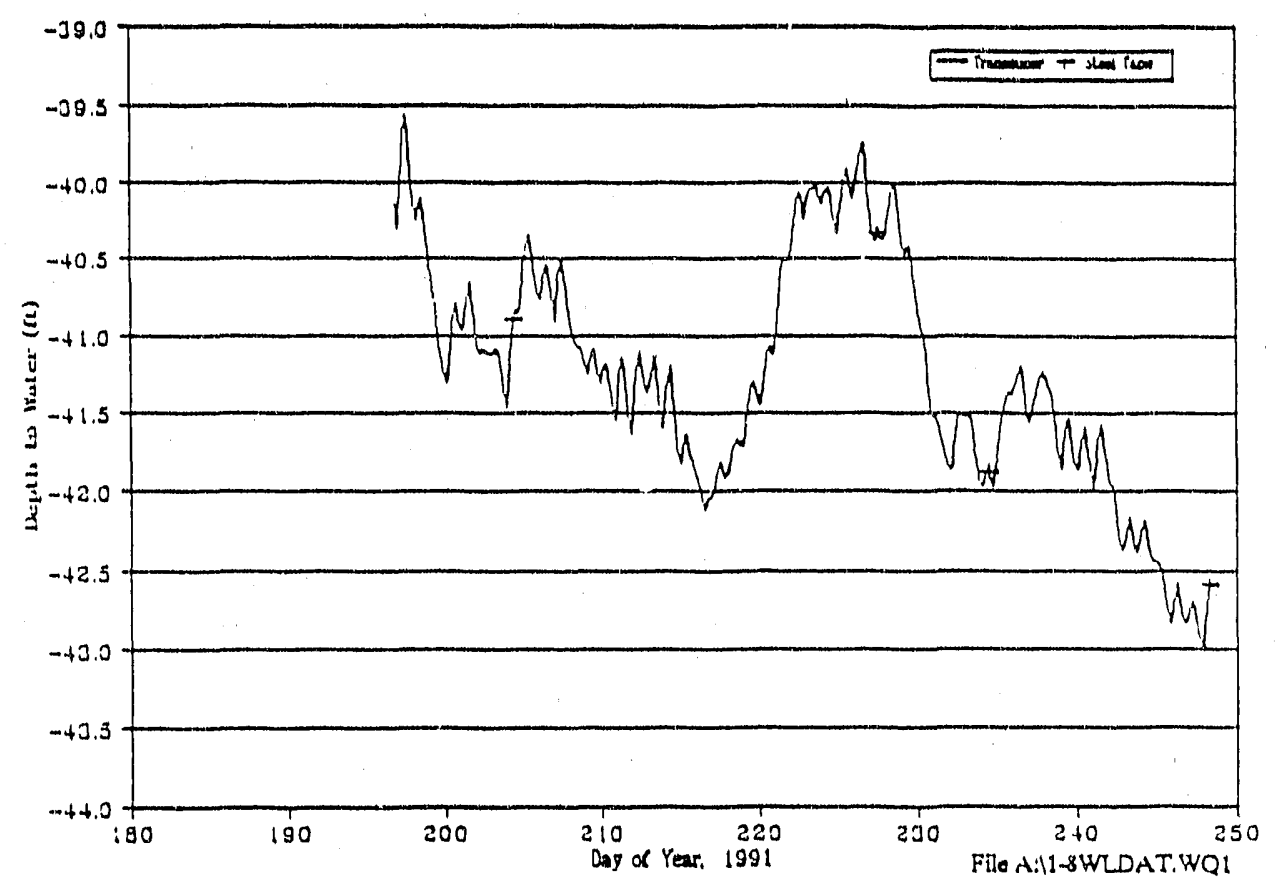

FIGURE 3.15. Comparison of Routine Transducer Measurements and Steel-Tape Measurements of Depth to Water Below the Top of the Casing for Wel1 399-1-8

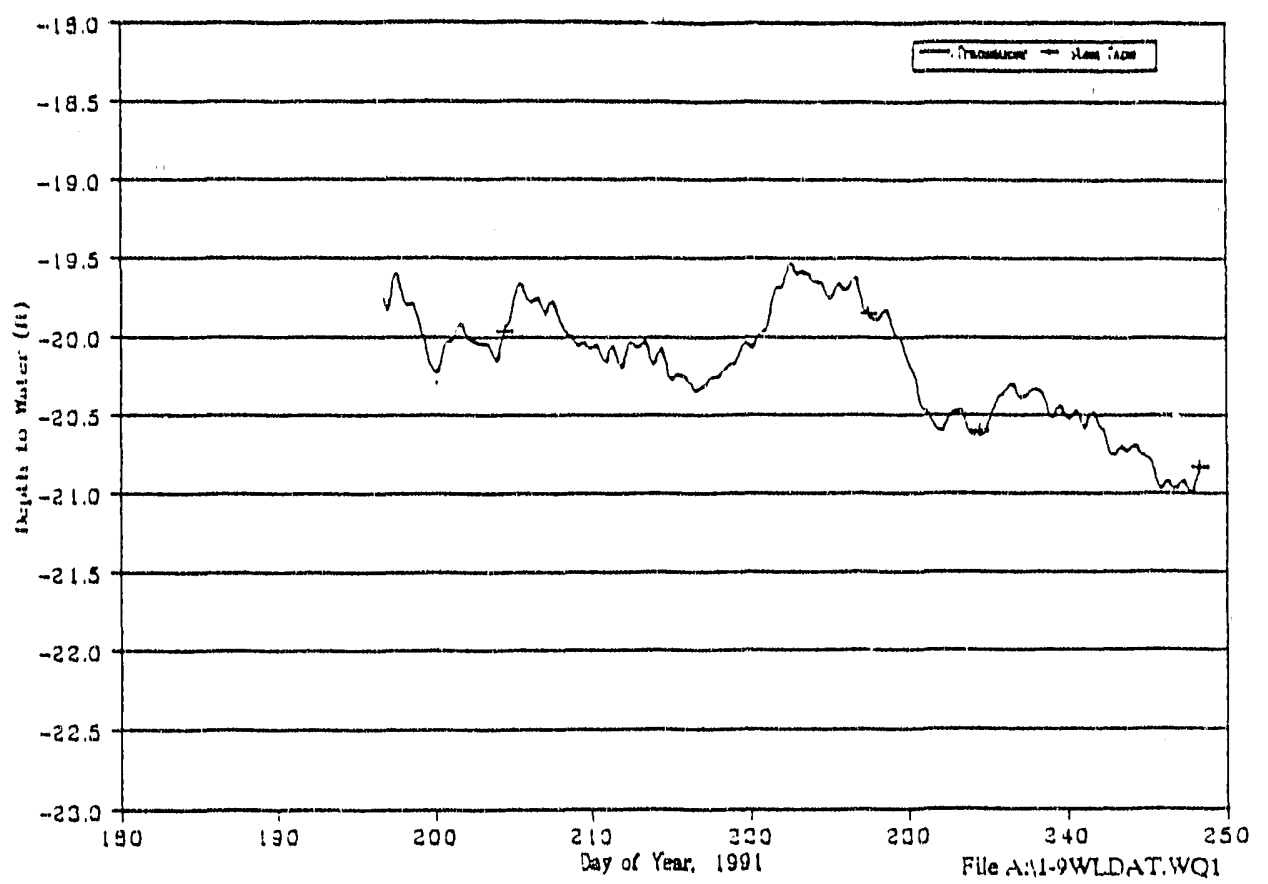

FIGURE 3.16. Comparison of Routine Transducer Measurements and Stee1-Tape Measurements of Depth to Water Below the Top of the Casing for We11 399-1-9 


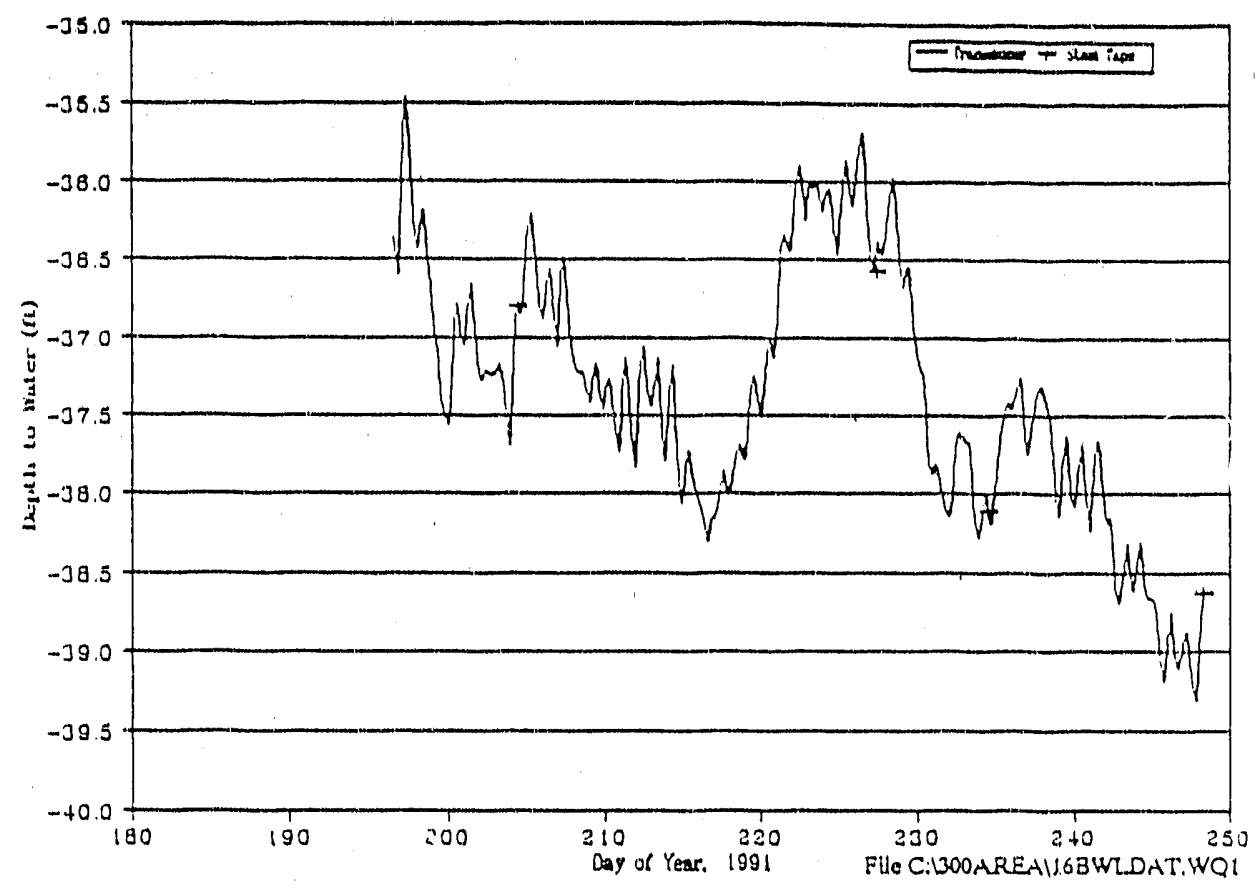

FIGURE 3.17. Comparison of Routine Transducer Measurements and Stee T-Tape Measurements of Depth to Water Below the Top of the Casing for We11 399-1-16B

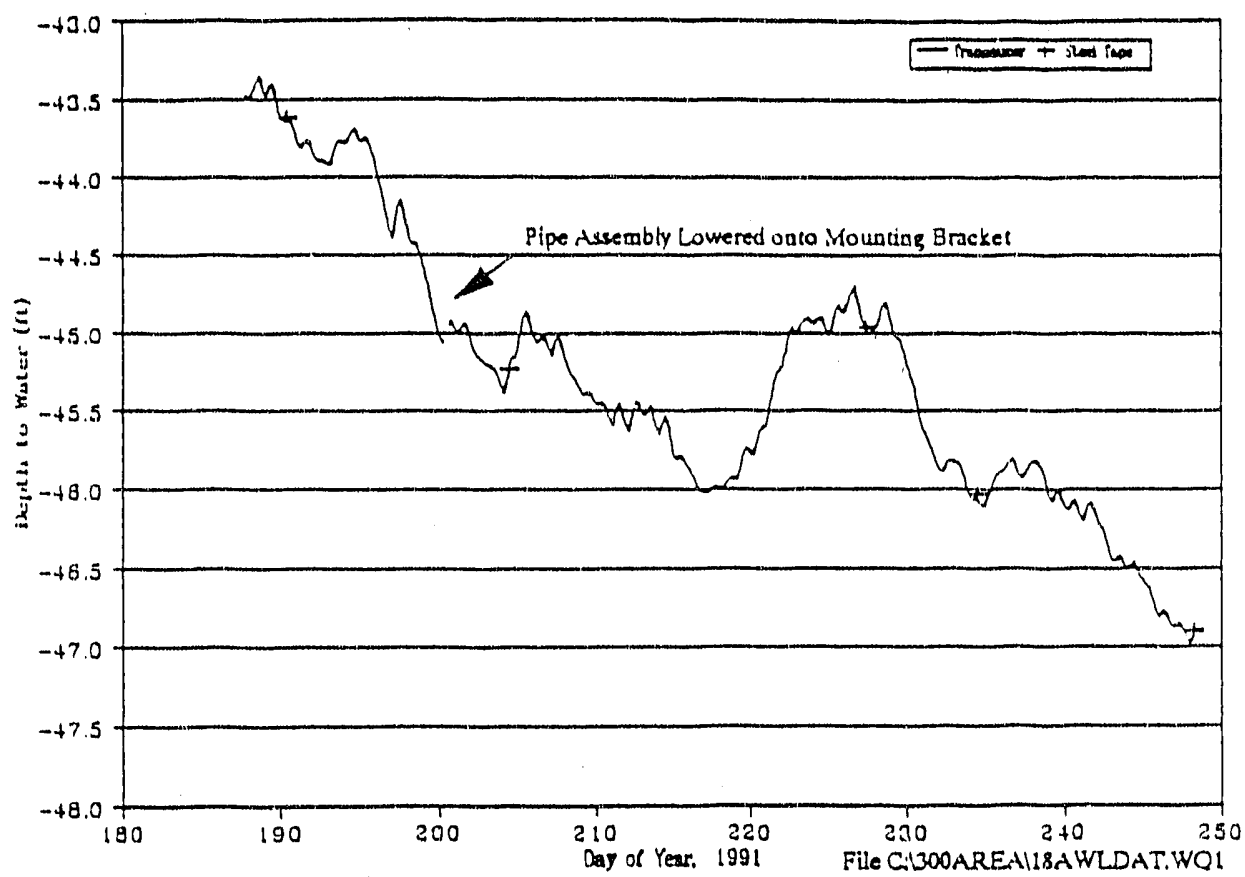

FIGURE 3.18. Comparison of Routine Transducer Measurements and Stee1-Tape Measurements of Depth to Water Below the Top of the Casing for We11 399-1-18A 


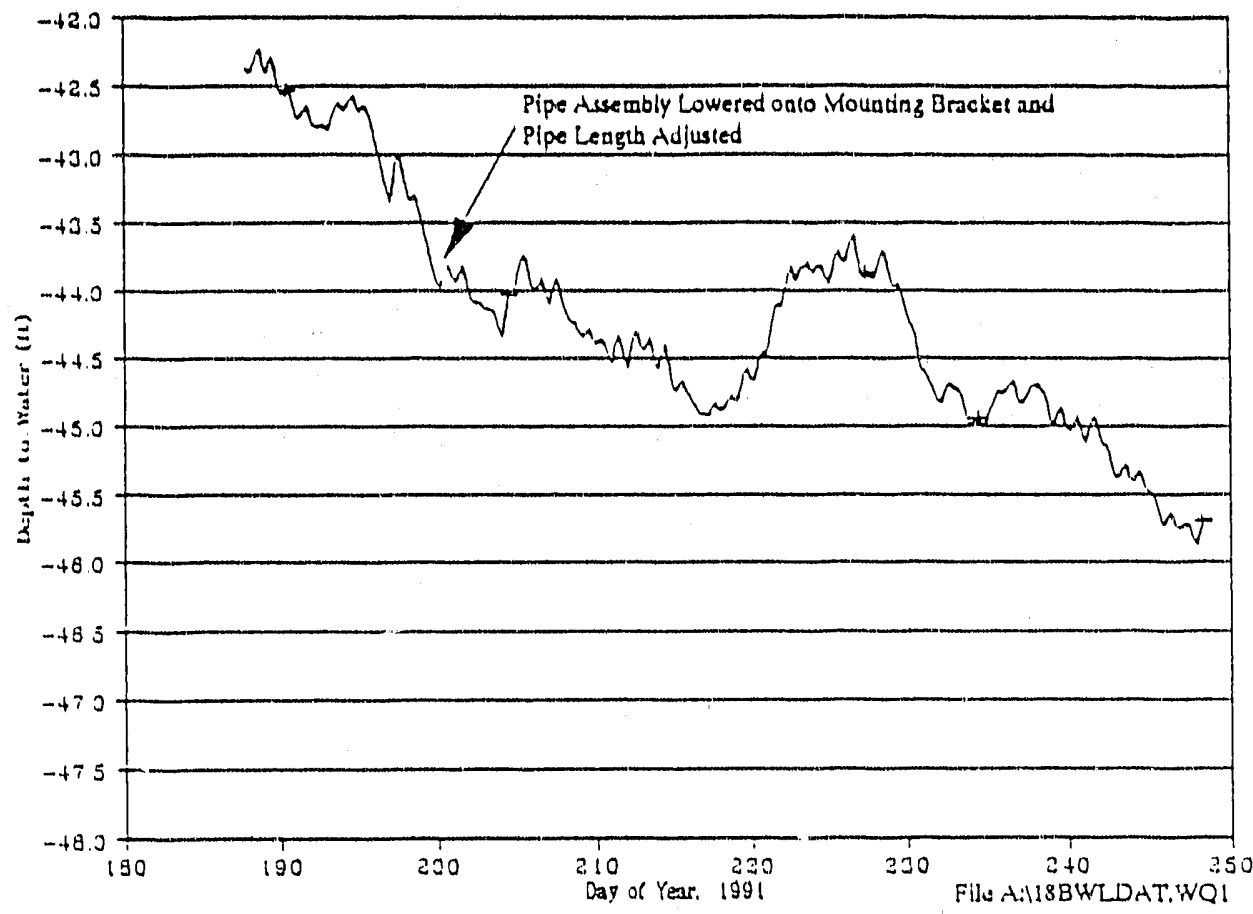

FIGURE 3.19. Comparison of Routine Transducer Measurements and Steel-Tape Measurements of Depth to Water Below the Top of the Casing for We11 399-1-18B

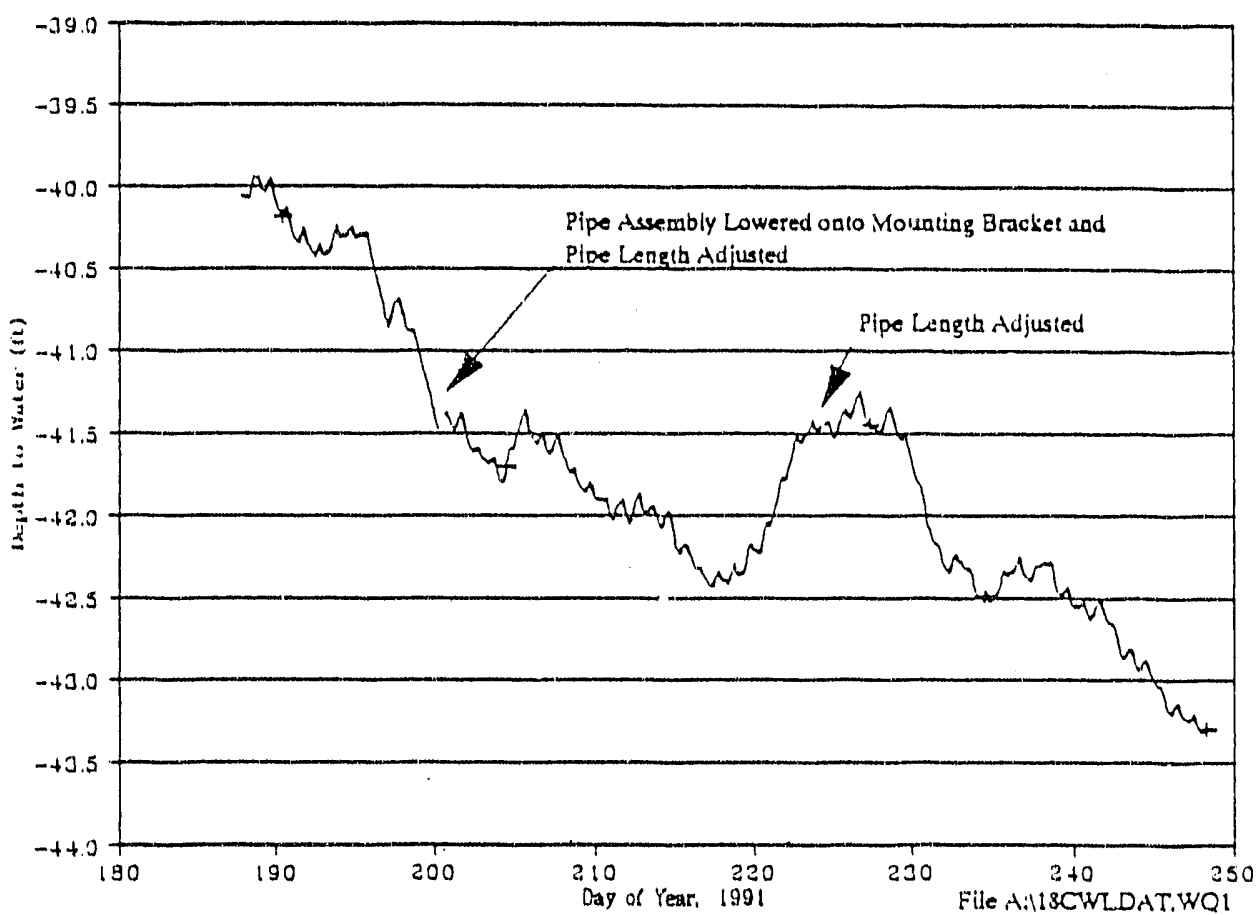

FIGURE 3.20. Comparison of Routine Transducer Measurements and Stee1-Tape Measurements of Depth to Water Below the Top of the Casing for We11 399-1-18C 


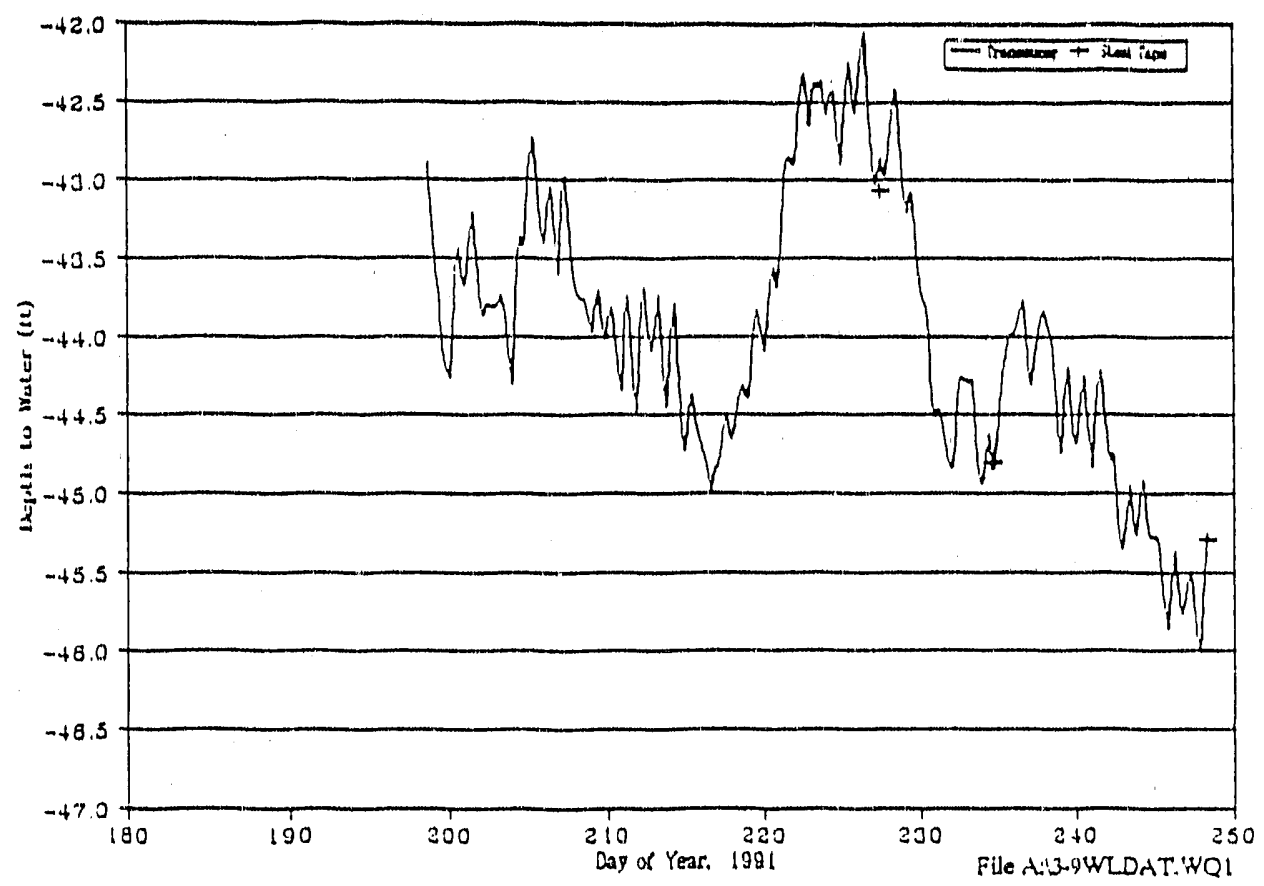

FIGURE 3.21. Comparison of Routine Transducer Measurements and Stee1-Tape Measurements of Depth to Water Below the Top of the Casing for We11 399-3-9

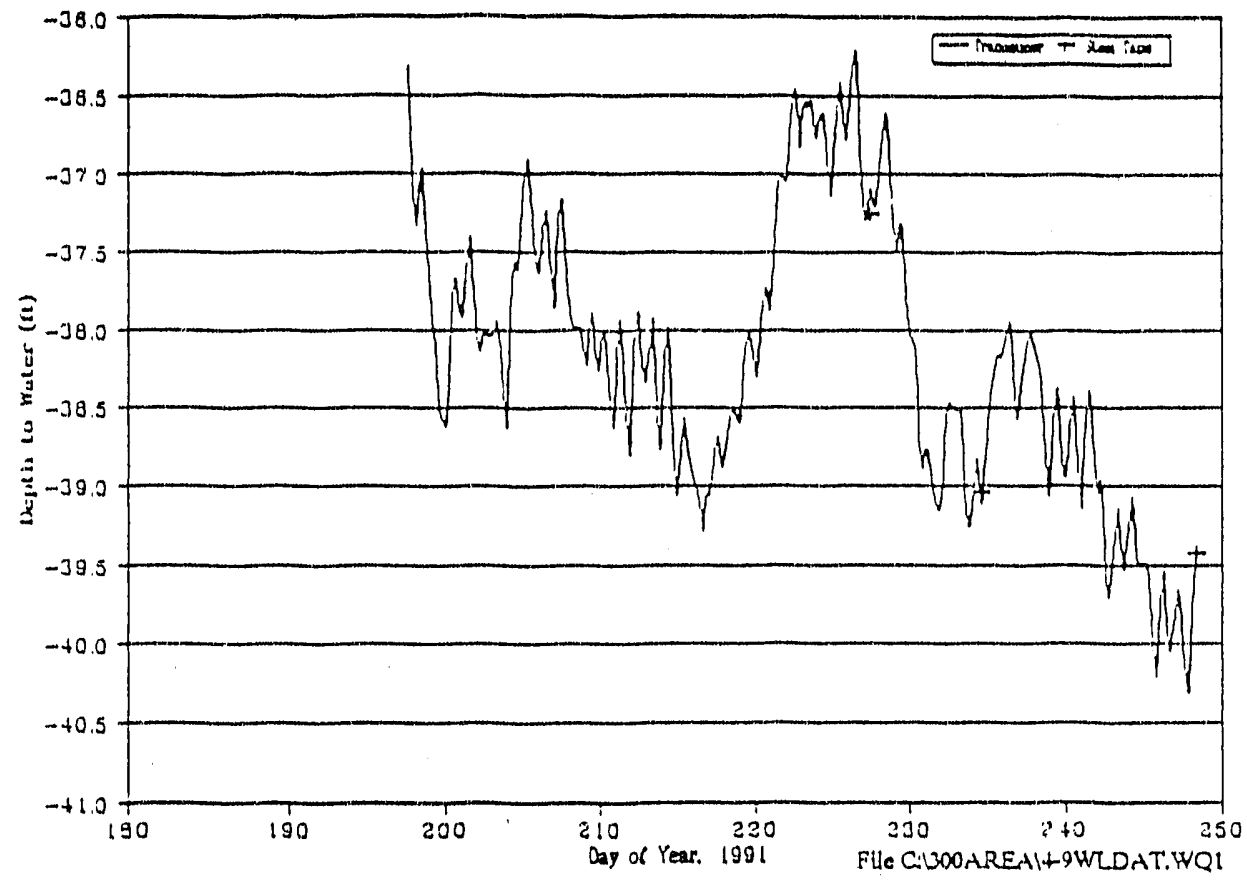

FIGURE 3.22. Comparison of Routine Transducer Measurements and Steel-Tape Measurements of Depth to Water Below the Top of the Casing for We11 399-4-9 


\subsection{CONCLUSIONS}

Automatic measurement and telemetry of water levels in wells is an effi.. cient and reliable method of obtaining aquifer water level data necessary for site characterization and remediation. A key factor in the reliability is the in situ calibration of pressure transducers. The accuracy of the method is not presentiy known because steel-tape measurements have not proven sufficiently reliable, but it appears to be within $\pm 0.02 \mathrm{ft}$, and possibly better. In situ calibration takes into account liquid physical property effects that influence hydraulic driving forces, including temperature, density, depth, floatables, solutes, and multiphase systems. Accurate recalibration is possi. ble without removal from the test we11, even during moderate changes in water elevation. It is apparent that the present design of the automatic monitoring system is capable of fulfilling the objective of this work which was to measure water levels in aquifers beneath the Hanford Site economically with increased frequency without sacrificing data quality. 


\subsection{REFERENCES}

Campbe11, M. D., R. Scha11a, and D. R. Newcomer. 1991. Accuracy and Cost Effectiveness of Manual and Automated Water-Level Monitoring Technology. PNL-7566, Pactfic Northwest Laboratory, Richland, Washington.

U.S. Envtronmental Protection Agency (EPA). 1986. Resource Conservation and Recovery Act (RCRA) Ground-Water Monitoring Technical Enforcement Guidance Document. OSWER-9950.1, EPA, Washington, D.C. 


\section{APPENDIX}

Datalogger Program:

* 1 A 3600 A

(this plus the following causes scan each hour)

P $78 \quad$ Prectston

11 High Preciston

P 9 6-Wire Voltage Bridge with Excltation

11 Reps (add I for each transducer connected)

225 Excitation Range

323 Bridge Measurement Range

41 Input Chanrie1

51 Excitation Channel

62500 Excitation Millivolts

71 Location

81 . Multipliter

90 offset

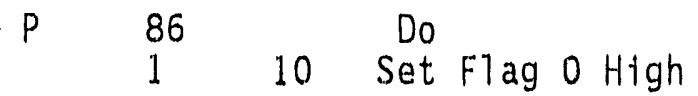

P $77 \quad$ Real Time

1110 Day:Hr:Min

P $70 \quad$ Sample

$\begin{array}{lll}1 & 1 & \text { Reps } \\ 2 & 1 & \text { Location }\end{array}$

A. 1 


\section{DISTRIBUTION}

No. of

Coples

\section{OFFSITE}

12 DOE/Office of Sclentific and Technical Information

6 DOE Office of Civilian Radloact tve Waste Management Forestal Butlding

Washingtom, DC 20585

ATTN: L. H. Barrett, RW-33

C. R. Cooley, RW-40

J. R. H Hlley, RW-30

S. H. Kale, RW-20

D. E. Shelor, RW-32

R. Stein, RW-23

2 Idaho National Engineering Laboratory

P.0. Box 1625

Idaho Falls, ID 83415

ATTN: J. B. Sisson

Technical Library

W. Moore

Office of High-Level Nuclear Waste Management

Washington State Department of Ecology

01 ympia, WA 98504

\section{ONSITE}

3 DOE Richland Field Office

R. E. Gerton, A4-02

J. M. Hennig, A5-21

G. W. Rosenwald, A4-02

23 Westinghouse Hanford Company

M. R. Adams, H4-55

J. W. Camman, H4-14

R. A. Car? son, H4-55

J. A. Coates, H4-56
No. of

Coptes

C. D. Delaney, H4-56

L. P. Dledtcker, T1-30

D. A. Duranceall, H4-14

K. R. Fecht, H4-56

i.. C. Hul strom, H4-55

I.. L. Jackson, H4-56

W. A. Jordan, H4-56

f., L. Kasza, H5-29

G. G. Kelty, H5-29

A. J. Knepp, H4-56

A. G. LaW, H4-56

R. E. Patersorr, H4-56

S. J. Pht111ps, L4.2.26

K. R. Stmpson (3), H5-2.

J. C. Sonnlchsen, H4-14

L. C. Swanson, H5-29

Public Reading Room

44. Pactfic Northwest Laboratory

J. V. Borghese, K6-96

R. W. Bryce, K6-96

M. D. Campbe11 (20), K6-77

J. W. Falco, $\mathrm{K} 6-78$

W. R. Gorst, K6-86

R. H. Gray (2), K1-33

P. C. Hays, K6-86

C. T. Kincaid, K6-77

S. P. Luttre11, K6 -96

D. R. Newcomer (3), K6-96

W. T. Pennel1, KG-04

L. E. Rogers, P7-54

R. Schalla, K6-96

R. L. Skaggs, K6-77

F. A. Spane, K6-96

P. D. Thorne, K6-96

Publishing Coordination

Technical Report Files (5) 

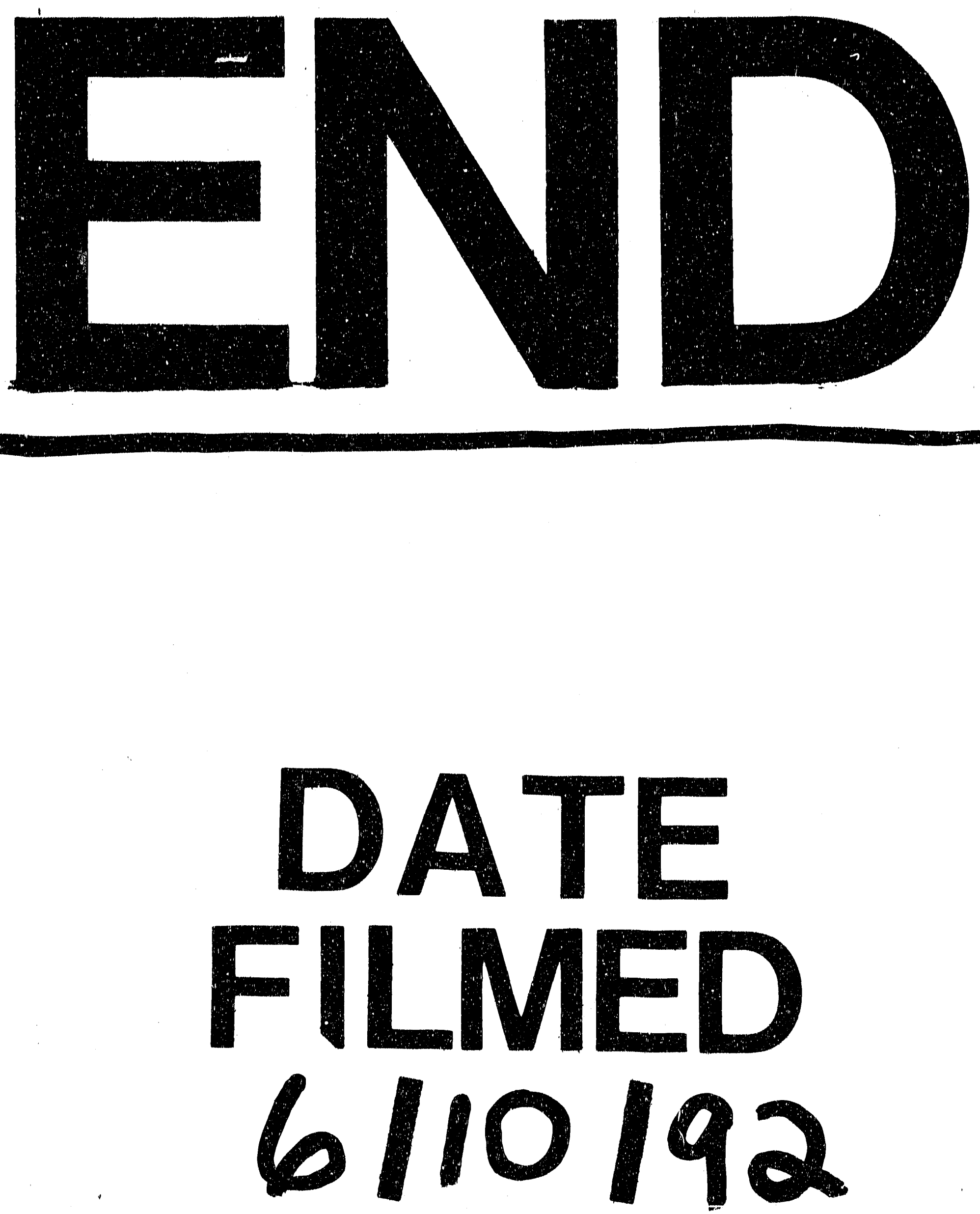


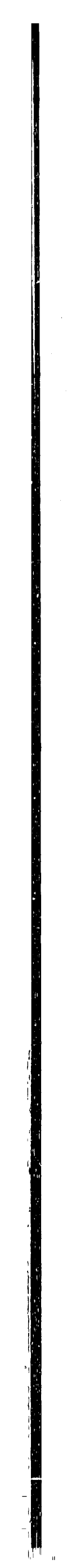

